\title{
pnmbalina
}

(8)

\section{Medea en la ópera}

Autor(es): $\quad$ Morán Rodríguez, Carmen; Pérez Benito, Enrique

Publicado por: Imprensa da Universidade de Coimbra; Universidad de Valladolid

URL

persistente: URI:http://hdl.handle.net/10316.2/32308

DOI: $\quad$ DOI:http://dx.doi.org/10.14195/978-989-26-0472-5_8

Accessed : $\quad$ 26-Apr-2023 07:51:43

A navegação consulta e descarregamento dos títulos inseridos nas Bibliotecas Digitais UC Digitalis, UC Pombalina e UC Impactum, pressupõem a aceitação plena e sem reservas dos Termos e Condições de Uso destas Bibliotecas Digitais, disponíveis em https://digitalis.uc.pt/pt-pt/termos.

Conforme exposto nos referidos Termos e Condições de Uso, o descarregamento de títulos de acesso restrito requer uma licença válida de autorização devendo o utilizador aceder ao(s) documento(s) a partir de um endereço de IP da instituição detentora da supramencionada licença.

Ao utilizador é apenas permitido o descarregamento para uso pessoal, pelo que o emprego do(s) título(s) descarregado(s) para outro fim, designadamente comercial, carece de autorização do respetivo autor ou editor da obra.

Na medida em que todas as obras da UC Digitalis se encontram protegidas pelo Código do Direito de Autor e Direitos Conexos e demais legislação aplicável, toda a cópia, parcial ou total, deste documento, nos casos em que é legalmente admitida, deverá conter ou fazer-se acompanhar por este aviso. 
Emilio Suárez de la Torre

Maria do Céu Fialho

(Coordinadores)

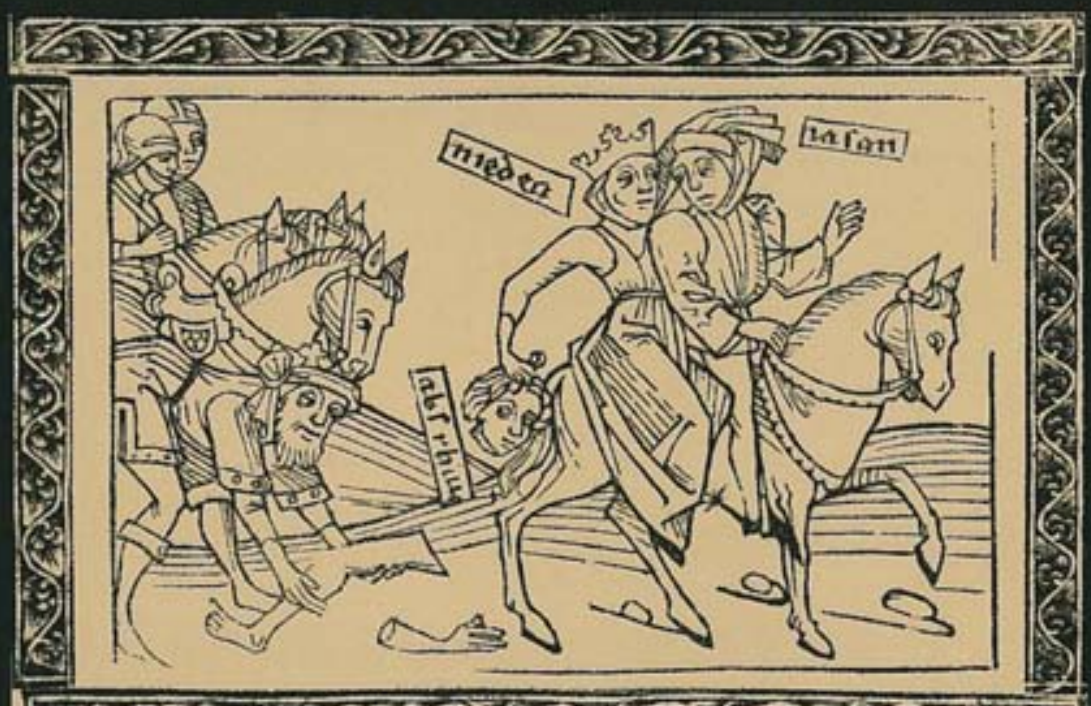

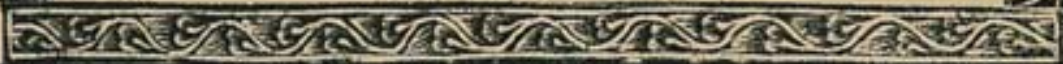

\section{BAJO EL SIGNO DE MEDEA}

\section{SOB O SIGNO DE MEDÉIA}




\title{
Medea en la ópera
}

\author{
CARMEN MORÁN RodrígueZ \\ ENRIQUE PÉREZ BENITO \\ Universidad de Valladolid
}

El presente trabajo es un acercamiento, no exhaustivo, a algunas de las manifestaciones musicales operísticas que han tomado como fuente de inspiración el mito de Medea ${ }^{(1)}$. Para adentrarnos en la cuestión es necesario, primero, hacer ciertas observaciones - mínimas- acerca de la naturaleza teatral del género operístico.

Comencemos por afirmarlo taxativamente: la ópera es una forma de teatro musical, y el relieve de su dimensión musical no debe hacernos perder de vista su dimensión dramática, de la que no puede prescindirse pa-

(1) Punto de partida inestimable para este artículo ha sido el monumental trabajo de J. Davidson Reid, The Oxford Guide to Classical Mythology in the Arts, vol. II, Oxford University Press, Oxford, 1993; también apreciable es el estudio de Donald M. Poduska "Classical Myth in Music" (CW, 92.3, 1999, 195-276). Este trabajo se encuentra también disponible en Internet (http://www.jcu.edu/myth\&music), con información actualizada sobre nuevas grabaciones de obras ya citadas en el artículo original, y sobre creaciones recientes. Para las informaciones relativas a compositores y libretistas, la fuente consultada de manera sistemática ha sido S. Sadie, (ed.), The New Grove Dictionary of Opera, 4 vols., New York, 1992. Para evitar una enojosa profusión de notas a pie de página, a partir de ahora siempre que citemos estas fuentes básicas lo haremos entre corchetes, en el cuerpo del texto principal: [Oxford Guide], [Grove], [Poduska]. Salvo indicación, la entrada consultada en Poduska y The Oxford Guide ha sido Medea (231-233). Para las búsquedas realizadas en The New Grove Dictionary, indicaremos la entrada o entradas consultadas en cada caso. Por razones de extensión nos hemos limitado a aquellas óperas que tienen a Medea por protagonista, $y$ hemos renunciado a hacer el censo completo de todas aquellas en las que aparece como personaje (las numerosas óperas que tienen a Teseo o a Jasón por protagonista principal, y en que Medea desempeña un papel más o menos secundario). No obstante, sí hemos incluido noticia de aquellos casos en que consideramos que alguna de estas óperas presentaba un interés especial (por ejemplo, Il Giasone de Cavalli, o el Thesee de Quinault y Lully, insoslayables por ser las primeras apariciones de Medea en el teatro operístico). 
ra comprender la ópera en su totalidad. Pero el vínculo de este género con el teatro es doble: por una parte, la ópera es, tipologicamente, teatro: se articula en unidades narrativas dramáticas (diálogo, monólogo, escena, acto); éstas configuran un texto (libreto) que se actualiza mediante una representación dramática. El propio término ópera es, en realidad, abreviación del sintagma opera in musica. Sin la coletilla, hoy perdida, opera significaba en latín 'obra', sin más; algo más específicamente podía referirse a la obra artistica y, en un contexto todavía más preciso, obra teatral en particular. Pero no la obra lírica que hoy llamamos ópera, y que necesitaba la precisión in musica. No afecta, por tanto, a la naturaleza de la ópera el que en unas épocas los gustos hayan tendido a enfatizar lo musical, otorgando menos importancia a los textos, considerados poco más que mera disculpa para el lucimiento de los cantantes.

Por otro lado, desde una perspectiva histórica, la ópera es teatro de manera muy especial ya que, en un determinado momento, la ópera fue - $\mathrm{O}$ al menos aspiró a ser- heredera legítima del teatro por antonomasia: la tragedia griega. Sin entrar en más detalles acerca de la compleja formación del género operístico, diremos que en su origen se encuentra el descubrimiento de que, originariamente, las tragedias griegas no eran declamadas, sino cantadas de principio a fin - tesis que hoy se ha probado falsa-. El prestigio de la Antigüedad griega en el Renacimiento explica la sorpresa y el entusiasmo con que la Camerata fiorentina recibió este descubrimiento, y el deseo de emular a los antiguos con un teatro musical monódico ${ }^{(2)}$.

Además, desde su nacimiento, la ópera convive con el teatro declamado, y ambas formas se retroalimentan (la dirección más frecuente, con todo, va del teatro declamado a la ópera). Así, la filiación tipológica con el género teatral explica la atracción de las primeras óperas por los argumentos mitológicos (muy frecuentados también por el teatro cortesano no operístico). Por su parte, la filiación histórica con la tragedia griega, a la que aspiraba a emular, haría perfectamente comprensible la elección recurrente de un tema tratado por Eurípides ${ }^{(3)}$. Medea contaba con todas las

(2) R. Alier, Historia de la ópera, Ma non troppo, Barcelona, 2002, 26 y ss.

(3) De todos modos, la filiación directa con el corpus de las tragedias griegas no importaba tanto como la recuperación de su espíritu y de su forma (acción dramática desarrollada mediante diálogos entonados como cantos monódicos). En general, más que la adaptación directa de obras de los trágicos griegos, se perseguía la evocación del mundo mitológico en argumentos que recreaban amores y contratiempos - como en tantas obras cortesanas, por otra parte-. De ahí la importancia de Ovidio - sobre todo de las Metamorfosis, aunque también en algunos casos de las Heroidas-como proveedor de historias conmovedoras sobre amores frustrados de personajes mitológicos (F.N. Sternfeld, The Birth of Opera, 
bazas para convertirse en un argumento operístico de éxito: al referente remoto de la tragedia antigua se fueron sumando sucesivas versiones de teatro declamado, $y$ gracias a ello pronto se contó, además, con una tradición de Medeas operísticas hacia la que volver la vista.

Será necesario hacer una precisión más antes de pasar a examinar el recorrido de Medea por la historia de la ópera. Hemos insistido hasta aquí en la dimensión dramática de esta forma de teatro musical, comprendiendo en tal dimensión dramática lo textual y mimético. Pero es necesario reparar en que el elemento musical no se limita a ser acompañamiento de un texto y una representación, sino que una parte importante del contenido dramático descansa en él ${ }^{(4)}$. En la ópera, la música también narra o representa, subrayando, completando, matizando o incluso contradiciendo lo que se narra o representa con palabras y gestos. Naturalmente, un personaje como Medea, que se presta a la escenificación de monólogos con numerosas y sutiles inflexiones psicológicas, a parlamentos ambiguos, etc., potencia la utilización de muy variados recursos musicales, y un estudio de mayor envergadura que el presente encontrará aquí un vasto terreno sobre el que trabajar.

A pesar de que, como hemos dicho, es a la forma dramática genéricamente llamada ópera a la que vamos a ceñirnos, no quisiéramos pasar por alto la mención de algunos ejemplos que prueban cómo la princesa de la Cólquide ha servido de inspiración para otras formas musicales, que pueden ser vocales o no, $\mathrm{y}$ tener un cierto componente de mímesis dramática (como es el caso del ballet o incluso puede serlo de las cantatas), o no tenerlo en absoluto. Una lista completa puede encontrarse en el citado trabajo del profesor Donald M. Poduska, que incluye referencias de las grabaciones existentes en cada caso. Contamos, por mencionar solo algunos títulos, con una Medea: Suite (1898) de Vincent d'Indy, con un experimento como Prism (1980), en el que Jacob Druckman (1928-1996) evoca las óperas de Cavalli, Charpentier y Cherubini, o con una compo-

Clarendon Press, Oxford, 1995, 5-6). El caso de Medea es singular, pues además de que Eurípides había legado en una tragedia la forma del mito que con el tiempo sería considerada "canónica", también Ovidio le había dedicado su atención en Metamorfosis VII y Heroidas VI, XII.

(4) Sobre este hecho han profundizado diversos trabajos en los últimos tiempos; entre ellos, el de L. Zopelli, Lopera come racconto. Modi narrativi nel teatro musicale dell'Ottocento, Marsilio, Venezia, 1994, de gran interés. En é, Zopelli estudia el sistema semiótico de la ópera como un sistema dual, compuesto por dos canales de comunicación simultáneos y paralelos, el del diálogo teatral (palabra y representación) y el de la expresión musical (Zopelli, op. cit., 17-8), y analiza el modo en que la música significa en el drama, con respecto al punto de vista de los personajes, a la perspectiva autorial, etc. 
sición de música coral, Choruses for Medea (1995), de Edison Denisov (1929-1966) [Poduska]. En el presente trabajo hemos considerado solamente óperas en el sentido pleno de la palabra, cińńndonos a obras dotadas de un auténtico desarrollo dramático. Por esta razón no tomamos en consideración las varias cantatas existentes: la compuesta para soprano y coro por Louis-Nicholas Clérambault (1676-1749), la de Antonio Caldara (ca. 1670-1736) para contralto y coro, la Médée de Jean-Philippe Rameau (1683-1764), cuya música no se ha conservado, la Médée et Jason, de Philippe Courbois (1705-30), o la paródica de Michel Corrette (17091795). Tampoco nos detendremos en la Medea de Iannis Xenakis (1967), música para un coro de voces masculinas con acompañamiento instrumental, que Xenakis habría compuesto en 1967 para una versión de la $\mathrm{Me}$ dea de Séneca, llevada a escena por el director teatral Jorge Lavelli e interpretada por María Casares, bajo la dirección musical de Diego Masson. Idéntico criterio nos lleva a dejar fuera de esta selección el monólogo para mezzosoprano y orquesta Medea (1952) del compositor vienés de origen checo Ernst Krenek. Haremos, sin embargo, una excepción con otro monólogo, el compuesto por Rolf Liebermann con texto de Ursula Haas, titulado Medea Monolog; la razón de que sí dediquemos cierta atención a esta obra es que, como se verá, ha sido germen de una ópera, resultado también de la colaboración entre Liebermann y Haas.

El título "Medea en la ópera", que por su sencillez hemos preferido a otros posibles, no debe equivocarnos respecto a dos hechos paralelos y complementarios: ni Medea es una figura invariable, con un único perfil, ni la ópera es una categoría en la que todas las manifestaciones sean homogéneas. Parece seguro que antes de convertirse en el personaje literario que hoy es, encarnación de pasión arrebatada, hechicera y asesina, Medea fue una diosa benéfica, posiblemente sanadora, de la estirpe de las diosasmadre que recibían culto en Grecia y el Oriente Próximo - como Cibeles, Gea, Rea o Deméter ${ }^{(5)}$ _. Cómo sus antiguas atribuciones positivas fueron transformándose a través de las sucesivas versiones hasta hacer de ella la hechicera (con toda seguridad, por su pasado como sanadora), la asesina de su padre, de su hermano, de sus propios hijos..., consagrada principalmente por Eurípides, es una larga historia en la que no podemos detenernos $^{(6)}$. Ya pulida por la literatura, convertida la antigua deidad en personaje, su fortuna ha sido inmensa ( $\mathrm{y}$ a la vez, también lo han sido sus

(5) A. Moreau, "Médée antique", en P. Brunel, (dir.), Dictionnaire des Mythes Féminins, Éditions du Rocher, París, 2002, 1280.

(6) Véase A. Moreau, op. cit., 1280-1283. 
avatares, ya que cada nueva versión ha contribuido a añadir, eliminar, transformar... elementos diversos a aquella figura primigenia que se pierde en la lejanía). Un estudio riguroso de cada una de las óperas que aquí se mencionarán debería, por tanto, atender cuidadosamente al —en ocasiones muy complejo- entramado de refundiciones y reelaboraciones de materiales procedentes, bien de otras óperas, bien del teatro declamado, y en algunas ocasiones de otros géneros como la novela ${ }^{(7)}$. No puede olvidarse tampoco que "ópera" es una denominación genérica que comprende formas diferentes, géneros distintos con sus propias convenciones $y$ preferencias, que determinan el tratamiento de los temas.

Cronológicamente, la primera aparición de Medea en la historia de la ópera tiene lugar el 5 de enero de 1649, en el Teatro S. Cassiano de Venecia, cuando se estrena Giasone, de Francesco Cavalli. El libreto de este drama musical con prólogo y tres actos es obra de Giacinto Andrea Cicognini [Oxford Guide, s.v. Jason; Poduska, s.v. Jason; Grove, s.v. Giasone; Cavalli, Francesco; Cicognini, Giacinto Andrea]. El éxito alcanzado por Giasone no precisa más constataciones que el dato siguiente: fue la obra más representada a lo largo del siglo XVII, y el libreto contó con numerosas impresiones en distintas ciudades italianas, en ocasiones con variaciones en el título (así, por ejemplo, las ediciones romanas de 1671 y 1676 llevan el título Il novello Giasone; la de Génova de 1685, Il trionfo d'Amor delle vendette y la de 1690, impresa en Brescia, Medea in Colco), según la práctica, habitual en esta época, de poner en circulación escrita el teatro, no solamente musical. El argumento desarrolla el episodio inicial de la historia de Jasón y Medea con notable independencia respecto a la tradición, y notable complejidad dramática (la obra cuenta con catorce personajes con voz). Tanto musical como dramáticamente es el Giasone una obra que representa fielmente las tendencias de su tiempo (o, visto de otro modo, puede afirmarse que Giasone es una de las obras que han perfilado las características del barroco literario y musical). En lo musical, se ha señalado cómo Giasone ejemplifica el paso a una separación marcada entre recitativo y arias. Por lo que respecta a lo literario, la obra participa plenamente de las características del teatro barroco: las unidades dramáticas no se respetan, aparecen mezclados lo serio y lo cómico e incluso hay juegos de identidades

(7) Sin embargo, creemos que también en aquellos casos en que la fuente de inspiración directa del libreto ha sido una novela entra en juego la tradición previa de Medeas teatrales (musicales o no), como término de referencia intertextual y, frecuentemente, de contraste. Más adelante tendremos ocasión de comprobarlo con un ejemplo del siglo XX, la ópera Freispruch für Medea, del compositor Rolf Liebermann, con libreto de Ursula Haas a partir de su propia novela homónima. 
ocultas (en el primer acto sabemos que Medea y Jasón han sido amantes sin que él conociese la verdadera identidad de la dama). Rosand, en la entrada elaborada para The New Grove Dictionary of Opera, señala como fuente principal, aunque utilizada con mucha libertad por Cicognini, Las Argonáuticas de Apolonio Rodio. En efecto, la ópera se centra en los amores de Medea y Jasón en la Cólquide —episodio que había sido fijado para la tradición por Apolonio-, no en los crímenes y desdichas que tendrían lugar después, tras la llegada de la pareja a Corinto. Además, se retoma, si bien con marcada independencia respecto del modelo, otro episodio del viaje de los argonautas que había sido narrado por Apolonio de Rodas en el canto I de su poema: el encuentro de Jasón con Hipsípila, princesa de Lemnos ${ }^{(8)}$. En la ópera de Cavalli, el argumento reduce al mínimo el elemento de la obtención del vellocino, y se centra en la intrincada trama amorosa protagonizada por Jasón, Medea e Hipsípila, que en el libreto de Cicogni ha abandonado Lemnos en pos de su amado tesalio, y que cuenta con la ayuda de Orestes para recuperar el amor de Jasón. A esta rivalidad entre Medea e Hipsípila por el amor de Jasón se añade una trama amorosa secundaria: la de la pareja formada por Besso (capitán de la guardia de Jasón) y Alinda (dama de honor de Hipsípila). El enredo resulta muy complicado, como corresponde a un drama amoroso del teatro barroco cortesano, musical o no; al llegar la solución, en las últimas escenas, el parecido con la tradición del mito se reduce prácticamente a los nombres de los protagonistas: Jasón, para complacer a Medea, ordena la muerte de Hipsípila; por error su capitán Besso trata de matar a Medea arrojándola al mar, y cree haberlo logrado, pero ésta es salvada por Egeo,

(8) En la narración épica de Apolonio de Rodas, el episodio de Lemnos y el encuentro de Jasón y Medea son independientes: el primero tiene lugar antes de llegar a las costas de la Cólquide, cuando la expedición arriba a la isla de Lemnos, habitada únicamente por mujeres. Éstas habían dado muerte a todos los varones de la isla, salvo a Toante, el rey, al que su hija Hipsípila habia salvado metiéndolo en un cofre que arrojó después al mar. Las mujeres lemnias deciden recibir hospitalariamente a los viajeros y unirse a ellos para engendrar hijos que renueven y perpetúen la población de la isla. Hipsípila se une a Jasón, y otras mujeres lemnias a cada uno de los argonautas. El único que se abstiene es Heracles, a quien no le parece bien esta frívola demora en la empresa que les ocupa. Él es quien increpa a sus compañeros para reanudar el viaje y así, los argonautas se hacen de nuevo a la mar, a pesar de los ruegos de las mujeres lemnias, y en especial de Hipsípila, quien asegura a Jasón que el trono de la isla y ella misma le estarán aguardando si un día decide volver. Pero Jasón rechaza este ofrecimiento, y una vez que los argonautas partan de Lemnos, Hipsípila y Jasón no volverán a encontrarse. Medea no hace su aparición hasta el canto tercero de Las Angonduticas. El episodio de Lemnos es relatado en Apolonio de Rodas, Las Argonduticas, canto I, vv. 601-913. En la ópera, la historia de Hipsípila ha conocido notable popularidad, especialmente gracias a un libreto de Pietro Metastasio (1698-1782), titulado Issipile (1732), que fue representado repetidamente durante el siglo XVII y los comienzos del XIX con diversas partituras [Oxford Guide, s.v. Jason]. 
que a su vez trata de matar a Jasón... Medea, agradecida a Egeo por salvarle la vida y tratar de vengarla, le entrega su amor, e insta al tesalio a volver con Hipsípila [Grove, s.v. Giasone]. Como puede verse, se trata de un argumento cortesano en que varias parejas sufren por causa del amor, y que evoca convencionalmente -más a través de los nombres que de los episodios- la mitología clásica.

En Francia, durante la segunda mitad del siglo XVII, el tema también es muy frecuentado en la escena: lo prueban dos tragedias recitadas de Pierre Corneille, Médée (1635) y La Toison d'Or (1660), y una de Bernard de Longepierre, Médée (1694). Si consideramos la viveza del debate en torno a la moralidad de los argumentos que por estos ańos ocupaba a los dramaturgos franceses, no puede dejar de sorprender la popularidad del tema, escabroso, en principio, para ser representado sobre las tablas (en las del teatro musical, más aún, pues en él el goce estético predominaba sobre la catarsis). Consciente de ello, Pierre Corneille había puesto al frente de su Médée una justificación que salía al paso de los ataques que se le habían de hacer por poner en escena lo execrable. La defensa de Corneille se basa en la posibilidad de poner en escena, hermosamente, lo espantoso; dicho con sus propias palabras, es lícito al artista mostrar "belles imitations d'une ac-

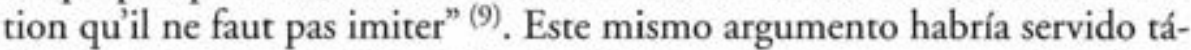
citamente para permitir el mito de Medea en representaciones de la ópera francesa - un teatro sumamente estilizado y espectacular en que las cuestiones morales, aunque presentes siempre, podían verse relegadas a segundo plano por la música, los ballets, etc. Con todo, puede ser significativo que la primera aparición de Medea en una ópera francesa sea como personaje secundario, en Thésée (estrenada en Saint Germain-en-Laye el 11 de Enero de 1675 y representada en la Opéra de París en abril del mismo año), de Jean-Baptiste Lully, con libreto de Philippe Quinault ${ }^{(10)}[$ Oxford Guide, s.v. Theseus $\left.{ }^{(11)}\right]$.

(9) Esta justificación es el objetivo de la carta "À Monsieur P.T.N.G.", epistola dirigida a un destinatario no identificado que el dramaturgo francés puso al frente de las ediciones de su tragedia (Pierre Corneille, Oeuvres completes I, Gallimard, Paris, 1980, 535-36; la cita se encuentra en la página 535).

(10) En 1782, el francés Morel hizo una adaptación del Thésée de Quinault para una partitura de Gossec.

(11) The Oxford Guide... puntualiza que el texto de Quinault era una tragedia "used as a libretto for operas by Lully (...) and at least 6 further composers to $1782^{\text {" }}$ [Oxford Guide, s.v. Theseus]; esta misma fuente incluye la referencia del singspiel titulado Theseus, de Nicolaus Adam Strungk (1640-1700), cuyo libreto escribió Ludwig von Bostel a partir del texto de Quinault, y que habría sido estrenada en 1683 en Hamburgo [Oxford Guide, s.y. Theseus]. 
Algo más tarde en ese mismo año, pero en el ámbito italiano, la ópera revisita el mito: Antonio Giannettini (o Zanettini, o Zannettini) (1648-1721) lo elige como argumento para Medea in Atene, su primera ópera, estrenada en Venecia el 14 de diciembre de 1675. Giannettini fue autor de varios oratorios y óperas que alcanzaron gran popularidad en su tiempo, y esta primera es una de las más conseguidas y reconocidas. Consta de un prólogo y tres actos, y el libreto es obra de Aurelio Aureli. Este mismo libreto fue aprovechado para una partitura de Bernardo Sabadini (?-1718); la nueva ópera se tituló Teseo in Atene y fue estrenada en Parma, en 1688 [Oxford Guide, s.v. Theseus; Grove, s.v. Giannettini, Antonio; Aureli, Aurelio; Sabadini, Bernardo].

Casi veinte años después, Medea vuelve a aparecer en la ópera francesa, esta vez como protagonista. El 4 de diciembre de 1693 se estrenó en el Teatro de la Ópera de París la "tragédie en musique" Médée, de Marc Antoine Charpentier ${ }^{(12)}$, con libreto de Thomas Corneille [Oxford Guide; Poduska; Grove, s.v. Charpentier, Marc Antoine; Corneille, Thomas; Médée].

A pesar de que cuando Médée se estrena hace ya seis años que Lully ha muerto, el dominio de sus criterios musicales seguía siendo absoluto en la Académie Royale de Musique francesa, y esto fue la causa de la tibia acogida dispensada a la obra de Marc-Antonie Charpentier. La obra resultó perjudicada por esta rivalidad entre lullistas e italianistas, a pesar de que a la Médée de Charpentier no le faltaban bazas para ser un éxito: el personaje principal fue interpretado por Marthe Le Rochois, una de las más célebres y reputadas cantantes de su tiempo (la misma que había interpretado buena parte de las óperas de Lully); además, el Delfín acudió a dos representaciones y el Duque de Orleáns a cuatro, según el Mercurio galante, y no faltó público que se mostrase favorablemente impresionado. Pero se representó únicamente en diez ocasiones ${ }^{(13)}$, y hasta el siglo XX la obra permaneció en un semiolvido injustificable, si atendemos a su calidad, comparable a la de las mejores composiciones de Lully, y más cercana que éstas a nuestra sensibilidad actual.

El libreto es obra de Thomas Corneille, quien era ya un dramaturgo reconocido y exitoso en el teatro declamado - hoy su fama ha quedado

(12) Es grande la carestia de datos fiables sobre la biografia de este músico; un meritorio esbozo biográfico es el realizado por C. Cessac, "Eléments pour une biographie", Lavant Scène Opera 68, 1993, 4-22.

(13) Una última representación, que tuvo lugar en Lille, el 17 de noviembre de 1700 , terminó accidentadamente, pues los decorados se incendiaron. La ópera no volvió a ser puesta en escena hasta el siglo XX (véase la página 18 del citado trabajo de Cessac; también J. Bégaud, "Loeuvre à l'affiche", L'Avant Scéne Opéra, 68, 1993, 124). 
eclipsada por la de su hermano Pierre-, y también tenía ya cierta experiencia como escritor de libretos. Aunque para la composición de este libreto Thomas Corneille toma en consideración la tragedia de Séneca y la que había escrito Pierre Corneille, en $1635^{(14)}$, el libreto no es una mera adaptación, sino una obra original y de calidad literaria. William Christie, el director de orquesta que más se ha esforzado por recuperar esta obra injustamente ignorada durante mucho tiempo, se pronuncia así sobre el libreto: "Thomas Corneille a écrit un des plus grands livrets qu'on puisse citer dans l'histoire de l'art lyrique français." (i5). Consta de cinco actos más un prólogo de carácter político encomiástico dirigido a la persona del rey Luis XIV.

Patrick Werly ha señalado que la principal diferencia entre la tragedia de Pierre Corneille y la ópera de Charpentier y Thomas Corneille es que la primera da a la historia un sentido político - Medea actúa en rebeldía contra las disposiciones tiránicas de Creonte-, mientras que la segunda prefiere enfatizar la faceta de hechicera de la protagonista, que da pie para desarrollar varias escenas espectaculares de gran efectismo ${ }^{(16)}$.

Antes de terminar el siglo aún encontramos una recreación más del mito en el contexto de la ópera francesa: Pascal Collasse (1649-1709), compositor francés discípulo de Jean-Baptiste Lully — para quien ejerció labores de secretario en la Académie Royale de la Musique - es autor de una "tragédie en musique" titulada Jason, ou La toison d'or, con libreto de JeanBaptiste Rousseau (1671-1741). La ópera consta de un prólogo y cinco actos. Estrenada en París, en 1696, fue acogida con frialdad (se mantuvo en

(14) Ésta se basaba a su vez en la tragedia del poeta latino, como el propio Pierre Corneille declaraba: "Ma Médée ne doit rien au poète grec, mais infinitement au latin (...)" (cit. en Oeuvres completes, I, 1377).

(15) "Laventure de la re-création", L'Avant Scene 68, 1993, 118.

(16) P. Werly, "Médée du XVI au XVIII ${ }^{e}$ siècle", en P. Brunel, (dir.), Dictionnaire des Mythes Féminins, Editions du Rocher, París, 2002, 1287. Por su parte, Dancourt —que no ve en la Médée de Pierre Corneille la puesta en escena de una confrontación política entre lo griego y lo no griego- ha notado cómo las sucesivas recreaciones del mito de Medea muestran un desplazamiento del centro de interés. La cualidad de hechicera de la princesa, que fue el aspecto más destacado hasta el siglo XIX, ha quedado relegada por su condición de bárbara, de extranjera, que ha sido el rasgo más atractivo del mito para la modernidad y la posmodernidad descolonizadora: " ${ }^{2}$ Médée la barbareo vient au premier plan de la scène moderne, reléguant l'image ancienne de la magicienne que privilégiaient la pièce de Corneille et l'opéra de Charpentier. Médée devient le lieu où soumettre la notion de "barbariew à un renversement de sens et à une opération de décentrement. Les artistes du XXe siècle font de Médée l'étrange étrangère, dépossédée de son identité et qui ne peut la recouvrer que dans une crise vertigineuse". (M. Dancourt, "Médée dans la culture européenne du XX" siècle", en P. Brunel, (dir.), Dictionnaire des Mythes Féminins, Éditions du Rocher, Paris, 2002, 1291). 
cartel menos de un mes). Esto pudo ser la causa de las desavenencias entre Collasse y Rousseau, quien, al parecer, acusó al compositor de plagiar a Lully [Grove, s.v. Collasse, Pascal; Rousseau, Jean-Baptiste].

A punto de iniciarse el nuevo siglo, la tradición germánica aporta un ejemplo más: en 1700, en Leipzig, se estrena Medea, ópera del compositor Johann Christian Schieferdecker (1679-1732). No hemos podido hallar información relativa a la autoría del libreto. Según The Oxford Guide... la partitura se ha perdido [Oxford Guide; Grove, s.v. Schieferdecker, Johann Christian].

En Francia la tradición se vigoriza: a la colaboración entre el músico Joseph-François Salomon (1649-1732) y el libretista Simon-Joseph Pellegrin (1663-1745) debemos una Médée et Jason en cinco actos (más un prólogo), estrenada en la Ópera de París, el 24 de abril de 1713. Pellegrin, debido a su condición de clérigo, firmó esta obra mundana de argumento mitológico con el pseudónimo de "La Roque". La crítica ha señalado como fuente utilizada por Salomon para su libreto las Metamorfosis de Ovidio [Grove, s.v. Salomon, Joseph-François; Pellegrin, Abbé Simon-Joseph]. Aunque prácticamente olvidada en la actualidad, Médée et Jason obtuvo entre sus contemporáneos mayor reconocimiento que la Médée de Charpentier, que hoy resulta más conocida. Así lo prueban su presencia en el repertorio desde la fecha de su estreno hasta 1749 y la existencia de parodias referidas a esta ópera ${ }^{(17)}$.

Entre la producción operística italiana del siglo XVIII se cuenta una ópera en tres actos titulada Medea e Giasone, compuesta por Giovanni Francesco Brusa (ca. 1700-después de 1768), con libreto de G. Palazzi (fl. 1718-1749). Fue estrenada en Venecia, en San Angelo, el 26 de diciembre de 1726.

Al parecer, el compositor italiano de ascendencia española David Perez (1711-1778) sería autor de una Medea estrenada en Palermo, en 1744 [Oxford Guide; Grove, s.v. Perez, David; ninguna de las dos fuentes especifica la autoría del libreto].

En 1752, en Rudolstadt, se estrena una Medea de Georg Gebel II (1709-1755), con libreto de J.G. Kloss. Al igual que el resto de óperas de este compositor, la Medea se ha perdido [Oxford Guide; Grove, s.v. Gebel].

(17) B. Pintiaux, "La tragédie amoureuse dans la tragédie en musique: l'exemple de Médie et Jason de Pellegrin et Salomon (1713)". Equinoxes. A Graduate Journal of French and Francophone Studies, 2, 1-9; en http://www.brown.edu/Research/Equinoxes/journal/issue2/ eqx2_Pintiaux.heml. 
Hacia 1760 ó 1761, el compositor inglés de ascendencia germánica John Christopher Smith (1712-1795) comienza la composición de una $\mathrm{Me-}$ dea, para la cual contaba con un libreto de Benjamin Stillingfleet; al parecer, la obra quedó inconclusa [Oxford Guide; Grove, s.v. Smith, John Christopher].

La existencia de una Medea del checo Josef Mysliveček (1737-1781), que se habría estrenado en 1764, en el Teatro Ducal de Parma [Oxford Guide, según esta fuente el autor del libreto sería Friedrich Wilhelm Gotter] parece dudosa [Grove, s.v. Mysliveček, Josef; Gotter, Friedrich Wilhelm].

En 1774 se estrena en Estocolmo una Medea de Bengt Lidner, que es autor de la música y el libreto [Oxford Guide].

Ya en el último cuarto del siglo XVIII, Georg Anton Benda (o Jirí Antonín Benda), compositor georgiano (1722-1795) es autor de un melodrama en un acto titulado Medea, estrenado el 1 de mayo de 1775, en Leipzig (Theater am Rannstädter Tor). El libreto es obra de Friedrich Wilhelm Gotter (1746-1797) [Oxford Guide; Poduska; Grove, s.v. Medea; Benda, Georg Anton; Gotter, Friedrich Wilhelm].

Una Médée compuesta en torno a 1784-86 por Antonio Sacchini (1730-1786), con libreto de Nicolás Étienne Framery (1745-1810), no habría llegado a representarse [Oxford Guide; Grove, s.v. Framery, Nicholas Etienne].

El compositor alemán Johann Cristoph Vogel (1756-1788) es autor de una tragedia lírica en tres actos titulada La toison d'or, con libreto de P. Desriaux, inspirada por y dedicada a Gluck. La ópera fue estrenada en la Ópera de París, el 5 de Septiembre de 1786, cuando habían pasado ya algunos años desde que Vogel terminase la composición. Para entonces, el cambio en los gustos hizo que la obra no resultase un éxito. Poco antes de morir Vogel, fue reestrenada con un título nuevo, Médée de Colchos. [Grove, s.v. Vogel, Johann Cristoph].

El compositor alemán Johann Gottlieb Naumann (1741-1801) compuso una Medea, conocida también como La partenza di Giasone da Colco o Il ritorno di Giasone in Grecia, con libreto de A. Filistri. Se estrenó en Berlín (Königliche Oper), en octubre de 1788. Revisada, se reestrenó bajo el título Medea in Colchide el 11 de febrero de 1805, en el mismo teatro de Berlín. [Oxford Guide, s.v. Medea, Jason; Grove, s.v. Naumann, Johann Gottlieb].

Gaetano Marinelli (1754-después de 1820) estrena La vendetta di Medea en el Carnaval de Venecia de 1792, en San Samuele [Oxford Guide; Grove, s.v. Marinelli, Gaetano; ninguna de las dos fuentes da información sobre la autoría del libreto]. 
Gaetano Andreozzi (1755-1826) compone una ópera titulada Giasone e Medea, que podría haberse estrenado en San Petersburgo en 1785, aunque tal vez la primera representación haya sido la que tuvo lugar en el San Carlo, de Nápoles, el 4 de noviembre de 1793. Hasta donde hemos podido saber, no se conoce la autoría del libreto [Oxford Guide; Grove, s.v. Andreozzi].

Luigi Cherubini es autor de Médée, en tres actos, con libreto de François Benoit Hoffman. Esta ópera se estrenó en París, en el Théâtre Feydeau, el 13 de marzo de 1797. Habitualmente se menciona como fuente del libreto de Hoffman la tragedia de Séneca o (con menos frecuencia) la de Eurípides. Lo cierto es que el texto dramático de Hoffman dista mucho de ser una adaptación; se trata de un drama original cuya deuda con las fuentes clásicas es la de toda obra que se inscribe dentro de una vasta tradición. El éxito de esta Médée ha sido variable: tras la veintena de representaciones que siguieron a su estreno fue olvidada en Francia hasta mediados del siglo XX; en el ámbito germánico, sin embargo, fue representada varias veces durante el siglo XIX. Pero la recuperación de esta ópera en los teatros del resto del mundo tendría lugar en la década de los cincuenta cuando Maria Callas hizo de éste uno de sus roles más célebres. [Oxford Guide; Poduska; Grove, s.v. Médée; Cherubini, Luigi; Hoffman, François Benott].

La vendetta di Medea, estrenada el 13 de agosto de 1798, en el Teatro de San Carlo, en Nápoles, es obra del compositor Francesco Piticchio (fl. 1760-1800) y el libretista O. Balsamo [Oxford Guide; Grove, s.v. Pitichio].

Todavía en el siglo XVIII contamos con una versión más de Medea. Nos referimos a la curiosa obra Os Encantos de Medeia, con música de António de Teixeira y texto de António José da Silva, llamado "O Judeu". Esta ópera fue estrenada en Lisboa, en el Teatro do Bairro Alto (Casa dos Bonecos), en mayo de $1735^{(18)}$.

(18) Véase M.C. de Brito, Opera in Portugal in the Eighteenth Century, Cambridge University Press, Cambridge, 1989, 21-22, 130. Acerca de esta reelaboración del mito en forma de comedia galante con final feliz contamos con varios estudios, como el de J. Oliveira Bara$\mathrm{ta}$, "Utopia e Realidade: os encantos de Medeia e o anel de Sacatrapo", en Medeia no drama antigo e moderno, Instituto Nacional de Investigaçáo Cientifica, Coimbra, 1991; o el más reciente de María de Fátima Silva, "Tragédia feita comédia. Os Encantos de Medeia do Judeu", en López, Aurora y Andrés Pociña (eds.) Medeas. Versiones de un mito desde Grecia hasta hoy, vol. II, Universidad de Granada, Granada, 2002, 819-846. Aunque de carácter más general, también resulta imprescindible el trabajo de de María Helena Rocha Pereira "O Mito de Medeia na Poesia Portuguesa", en López, Aurora y Andrés Pocína (eds.), op. cit., vol. I, 70-85 (que actualiza un trabajo de igual título, de fecha muy anterior, Temas Classicos na Poesia Portuguesa, Verbo, Lisboa, 1972, 23-26). 
En su Crónica de la ópera italiana en Madrid desde el año 1738 hasta nuestros dias (Madrid, 1878), Luis Cármena y Millán atestigua la representación de una Medea cruel, "ópera en dos actos, con poesía nueva", puesta en escena en los Cańos del Peral (Madrid), del 11 al 17 de febrero de 1801. Cármena y Millán no proporciona más datos sobre la autoría de la partitura y el libreto, que podría ser traducción de alguna de las ya numerosas óperas italianas que habían tratado el tema de Medea ${ }^{(19)}$.

En Francia, Georges Granges de Fontenelle (1769-1819) compuso en 1802 una Médée et Jason, con libreto de Jean-Baptiste Rousseau Milcent, que sería representada el 10 de agosto de 1813 , sin obtener demasiado éxito [http://www.musicologie.org/Biographies/f/fontenelle_granges.html; no aparece recogida en $O x f o r d$ Guide; Grove no dedica ninguna entrada al compositor ni al libretista].

Nuevamente en el marco de la ópera italiana, encontramos un ejemplo al que dedicaremos algunas líneas. Se trata del melodrama trágico en dos actos Medea in Corinto, estrenado en Nápoles, en el Teatro de San Carlo, el 28 de noviembre de 1813 [Oxford Guide; Poduska; Grove, s.v. Mayr, Johann Simon; Romani, Felice, Medea in Corinto]. Medea in Corinto es fruto de la colaboración de Giovanni Simone (o Johann Simon) Mayr (1763-1845) con un joven libretista, apenas conocido por entonces. El nombre del libretista era Felice Romani, y con el tiempo llegaría a ser uno de los más célebres de la historia de la ópera. Su melodrama trágico en dos actos Medea in Corinto, escrito originariamente para la música de Mayr, fue acompañado de otras dos partituras: la de Prospero Selli (Apolo, Roma, 4 de febrero 1839) y la de Saverio Mercadante (Nápoles, San Carlo, 1 de marzo 1851; en esta ocasión, la ópera se estrenó con el título de Medea y el libreto había sido modificado por Salvatore Cammarano). Con todo, la más célebre fue la versión original, con música de Johan Simon Mayr (San Carlos, Nápoles, 28 de noviembre de 1813) ${ }^{(20)}$. Mayr, hoy poco recordado, fue $\sin$ em-

(19) Cit. en Andioc, René y Miraille Coulon, Cartelera teatral madrileña del siglo XVIII (1708-1808), 2 vols., Praises Universitaires, Mirail, Toulouse, 1996. Sí nos informa Cármena y Millán, por el contrario, de detalles sobre la función en que se representó esta Medea cruel: en los días 11 a 16 de febrero fue seguida de un célebre fin de fiesta de la época, titulado "El no", y el 17 de febrero, de una obra en tres actos titulada Citas debajo del olmo. Estos datos resultan sumamente ilustrativos acerca de la realidad del espectáculo teatral en conjunto, desde el comienzo de la función hasta su fin - es decir, de lo que un espectador iba a ver y escuchar cuando iba al teatro, posiblemente a veces más interesado en el fin de fiesta que en la obra principal. Agradecemos a la profesora Irene Vallejo (Universidad de Valladolid) habernos puesto al corriente de la noticia de esta Medea cruel.

(20) Roccatagliati, Alessandro, Felice Romani librettista, Libreria Musicale Italiana, Lucca (Italia), 1996, 292. 
bargo un autor notablemente reconocido entre sus contemporáneos. Su formación musical más temprana tuvo lugar en tierras alemanas, donde había nacido en 1763 , pero pronto se trasladó a Italia (primero Bérgamo y más adelante Venecia), donde depuró sus cualidades y asimiló conocimientos y técnicas. Por ello se consideró siempre un músico italiano (hasta el punto de italianizar su nombre). Aunque su producción musical se había iniciado ya antes de llegar a Italia, y continuó allí, hasta 1794 no probó suerte en la ópera. Lo hizo con óperas trágicas, cómicas y tragicómicas, entre las que cabe destacar títulos como La Lodoiska (Venecia, 1796), I Misteri Eleusini (Milán, 1802), Elisa (Venecia, 1804) y Medea in Corinto (Nápoles, 1813). Medea in Corinto es, por su fecha, y más aún por sus cualidades, una obra de madurez artística. Le fue encargada por el prestigioso Teatro de San Carlo en Nápoles, que, según parece, quería una ópera al gusto francés, que complaciese a la corte francófila de Gioacchino Murat. Los recitativi secci de que Mayr dotó a su Medea en una primera versión, así como su idea original de dotar a Giasone de una voz de mezzo-soprano no habrian complacido al empresario, y Mayr fue instado a plegarse a los gustos franceses, que preferían el recitativo strumentato y apreciaban la voz de tenor más que la de mezzos y castrati. En el estreno, los papeles principales correspondieron a los siguientes intérpretes: Isabella Colbran como Medea, Luigia Pontiggia como Creúsa, Andrea Nozzari como Jasón y Manuel García como Egeo. El éxito fue considerable, incluso a pesar de los problemas de salud de la prima donna, aunque no faltaron críticos que encontraron excesivo mimo en la instrumentación en detrimento de las líneas vocales, contra lo que acostumbraba la tradición italiana.

Mayr, que contaba cuarenta y nueve años cuando Medea in Corinto se estrenó y se hallaba en una plenitud artística reconocida, había confiado para la confección del libreto en el joven de veinticinco años Giuseppe Felice Romani, que anteriormente había escrito un único libreto, también para Mayr, La Rosa bianca e la rosa rossa. Más adelante encontraremos su nombre de nuevo, esta vez como autor de una de las óperas más populares en el repertorio, Norma, que tiene interesantes conexiones con Medea.

Con Medea in Corinto, Romani tiene a su disposición un argumento mítico de incuestionable poder percusivo, que además contaba ya con una tradición de versiones y recreaciones vasta en el tiempo y el espacio, tanto en el teatro (musical y no musical) como en otros géneros. Romani se sirvió de los elementos que las sucesivas versiones le brindaban con flexibilidad ${ }^{(21)}:$ su

(21) Utilizamos para este breve resumen y comparación del libreto con las posibles fuentes el texto que acompaña a la grabación de Opera Rara; en esta edición pueden también 
Jasón está sinceramente enamorado de Creúsa; además, introduce personajes nuevos (como Acasto, al que se hace responsable de la orden de destierro contra Medea). Esta libertad, sin embargo, no es óbice para que desde el inicio mismo de la obra, Romani establezca un juego de contrastes con las versiones de raíz euripidea, a fin de cautivar a los espectadores. El libretista juega con las expectativas de un público que debe conocer la tradición del mito para apreciar el dramatismo de los parlamentos y de los giros de la acción. Así, por ejemplo, se aprecia en la primera escena del Acto I: la ópera se abre con la intervención de un grupo de sirvientas que tratan de calmar a su afligida señora. En la tragedia de Eurípides era también la voz de los siervos la que abría la escena: nodriza y pedagogo se intercambiaban las últimas noticias y sus mutuos temores, y después la nodriza trataba en vano de aplacar la furia desesperada de Medea. Pero - aquí viene el giro- en el texto de Romani las siervas son las doncellas del palacio de Corinto, y el ama que se lamenta no es la de Medea, sino precisamente la de su rival, Creúsa. En la escena segunda Creonte, Evandro y los hombres de Corinto hacen su entrada. Medea sigue siendo la protagonista por ausencia, y tampoco Jasón aparece, por más que Creúsa anhele su regreso y los corintios lo anuncien. La exposición del dilema se retrasa e incluso parece que Romani persigue confundir al auditorio. Es la guerra, no a Medea, lo que Creúsa teme, pues Jasón se encuentra luchando por Corinto. Los hombres anuncian su regreso triunfal a los brazos de la que ha de ser su esposa. Creonte refiere el motivo de la guerra: Acasto pretendía expulsar de Corinto a Jasón. La contienda ha terminado con un pacto: Medea debe abandonar Corinto. Desde la segunda escena sabemos que Creonte y su hija son completamente inocentes del destino que aguarda a Medea: ni lo han pedido ellos, ni lo han pactado ellos; lo valoran como un sacrificio, e incluso parecen favorables a una solución que hubiese permitido a Medea permanecer en Corinto. La diferencia con los modelos resulta más llamativa y dramáticamente más rica porque Medea no ha aparecido todavía en escena (no lo hará hasta la escena v de este primer acto), ni se conoce su reacción ante las aciagas nuevas, pero a la vez a ningún espectador se le oculta el rumbo trágico que van a tomar de un momento a otro unos acontecimientos, hasta entonces, casi completamente felices. Los gritos de

encontrarse, en un apéndice, las variantes de algunas escenas. En efecto, Mayr alteró la obra en varias ocasiones desde su estreno, como atestiguan las diversas versiones impresas del libreto. No son cambios sustanciales que modifiquen el desarrollo del argumento, sino principalmente cambios en la instrumentación y omisión de algunas líneas de texto que no afectan esencialmente a la obra. Con posterioridad a la redacción de este artículo, ha aparecido la edición crítica del libreto, acompañada de un estudio: Russo, Paolo, "Medea in Corinto" di Felice Romani: Storia, fonte e tradizioni, Olschki, Firenze, 2004. 
alegría de Creúsa ante la inminente llegada de Jasón cierran la escena como un presagio amargo. No podemos examinar detalladamente el desarrollo de la ópera, pero a lo largo de ella Romani continúa sirviéndose de este recurso - curiosamente tan euripideano- de engañar a los espectadores con alusiones ambiguas. Como, en realidad, ninguno ignora lo que va a suceder, el engaño se convierte en un desasosiego sabiamente administrado por Romani.

Varias Medeas aparecen en la ópera durante las primeras décadas del siglo XIX: el compositor napolitano Carlo Coccia (1782-1823) compuso un "dramma per musica", Teseo e Medea, que se estrenó en Turín, el 26 de diciembre de 1815 [Oxford Guide, s.v. Theseus; Grove, s.v. Coccia, Carlo; no da noticia de la autoría del libreto].

Una nueva ópera francesa titulada Médée sería obra de Edmée-Sophie Gail (1775-1819) [Oxford Guide; Grove no da cuenta de ninguna ópera de este título entre la producción de la compositora francesa, s.v. Gail [née Garre], (Edmée) Sophie].

Sin embargo, la más popular revisión del mito de Medea en la ópera de la primera mitad del siglo XIX no es precisamente una Medea, ni transcurre en el mundo grecolatino. Con todo, su relación con la hija de Eetes - notada repetidamente por la crítica - hace inexcusable que nos refiramos a ella. Naturalmente, hablamos de la ópera Norma, del músico Vicenzo Bellini y el libretista Felice Romani ${ }^{(22)}$. A su estreno, en La Scala de Milán, el 26 de diciembre de 1831, la obra recibió una fría acogida; sin embargo, el tiempo la ha convertido en una de las óperas favoritas del público.

David Kimbell señala tres fuentes para la elaboración del libreto: la tragedia en verso, en cinco actos, Norma ou l'infanticide, de Alexandre Soumet (estrenada con notable éxito en abril de 1831), la figura de Medea y la de Veleda, una sacerdotisa brúctera mencionada por Tácito (Historias IV, 61 y 65; V, 22 y 24), y a la que Chateaubriand convirtió, en 1809 , en coprotagonista - junto con su amado, el romano cristiano Eudoro- del libro IX de Les Martyrs ${ }^{(23)}$. Catherine Clément, al trazar el li-

(22) Para el análisis de Norma y su relación con Medea disponemos de dos excelentes monografias: la de David Kimbell para la colección "Cambridge Opera Handbooks" (D. Kimbell, Vincenzo Bellini: Norma, Cambridge University Press, 1998), y la realizada en colaboración por varios especialistas para la publicación bimensual L'Avant Scène Opéra, 29, septiembre-octubre, 1980. El ya mencionado estudio de Roccatagliati contiene valiosa información y copiosa documentación sobre la creación de este libreto.

(23) Kimbell, op. cit., 16-28. 
naje de heroínas que culmina en Norma sustituye a Veleda por Sofonis$\mathrm{ba}^{(24)}$, princesa cartaginesa cuya historia de amor y muerte nos ha llegado a través de Tito Livio (Ab Urbe Condita, libro XXX, 12-15) y recreaciones posteriores (Petrarca y Pierre Corneille, entre otros varios).

Personalmente, creemos que estas fuentes deben clasificarse en tres niveles de operatividad: tendríamos así, en primer lugar, el estrecho vínculo entre la ópera Norma y la tragedia de Soumet, Norma ou l'infanticide, que es su referente directo, indiscutible. El libreto de Romani se basa en este drama escrito al calor de la fiebre celtista que comenzaba a surcar Europa por estos años, y que la propia tragedia de Soumet, y la ópera más tarde, contribuyeron a avivar. Romani mantendrá la ambientación celta ${ }^{(25)}$, y seguirá con bastante fidelidad el argumento de Soumet, conservando, incluso, los nombres de los protagonistas. Con todo, Romani, hombre de gran talento para la escritura teatral, introduce algunos cambios significativos, y dramáticamente muy efectivos, en los que no podemos detenernos ${ }^{(26)}$. El argumento es de sobra conocido, por lo que nos limitaremos a esbozar un breve resumen: la acción tiene lugar en un bosque de la Galia, donde mora una tribu celta que realiza allí sus rituales sagrados en honor de Irminsul. Aguardan con ansiedad a que Norma, hija del jefe de la tribu (Oroveso) y sacerdotisa, corte el muérdago sagrado y anuncie que el dios aprueba la rebelión contra los romanos. En ese mismo bosque, pero ocultos a los galos, dos romanos conversan: el procónsul Pollione confiesa a su

(24) C. Clément, "Norma, Médée, Sophonisbe: de la séduction à la résistance", en L'Avant Scène Opéra 29, 1980, 12-15.

(25) Durante el siglo XIX, la literatura y las artes europeas quedaron fascinadas por un mundo celta a menudo más ideal que histórico. Para la ópera, esta moda celtista tenía el atractivo ańadido de la renovación temática, ya que hasta entonces los asuntos más frecuentados eran los de la mitología grecorromana, los poemas de Tasso y Ariosto o las historias de Boccaccio y Boyardo (Kimbell, op, cit., 19-20). Sin embargo, el conocimiento que Romani tenía del mundo celta era considerablemente más profundo que el de la mayor parte de sus contemporáneos fascinados por esta cultura: era autor, en colaboración con un colega (a partir de trabajos eruditos anteriores), de seis volúmenes aparecidos entre 1809 y 1825 bajo el título Dizionario d'ogni mitologia e antichità, incominciato da Girolamo Pozzoli sulle tracce del Dizionario della favola di Fr. Noel, continuato e ampliato dal Prof. Felice Romani e dal Dr. Antonio Peracchi (Kimbell, op. cit., 20). Romani recreó el mundo celta en otro libreto, para una ópera de Pacini titulada La sacerdotessa d'Trminsul, que se estrenó en mayo de 1820, en el Teatro Nuevo, de Trieste (Kimbell, op. cit., 22; sobre la relación entre ambos libretos, véase Kimbell, op. cit., 22-23). A Pacini volveremos a encontrarle algunos años más tarde, como autor de una nueva Medea.

(26) Mencionaremos únicamente el más importante de estos cambios, por afectar al desenlace de la obra: en el acto V de la tragedia de Soumet, Norma, enloquecida, da muerte a sus hijos. Acerca de este cambio, Kimbell se pronuncia en los siguientes términos: "By eliminating the final act, and with it the horror and the madness inherited from the Medea stories, he transforms the drama into a purely human tragedy (...)" (op. cit., 27-28). 
ayudante y amigo Flavio que ya no ama a Norma, su amante y la madre de sus hijos. Ahora está perdidamente enamorado de Adalgisa, una sacerdotisa más joven, quien le corresponde. Pero Pollione teme las iras de Nor$\mathrm{ma}$. Se acercan los galos para cumplir los rituales, y los romanos se ocultan. Toda la tribu ansía la orden divina que les permita marchar a la guerra contra Roma, pero Norma les advierte que la voluntad del dios es contraria al ataque, y que desobedecer solo traería la perdición de la tribu. Roma — profetiza Norma - caerá por sus propios vicios. Naturalmente, la razón por la que Norma refrena a sus compatriotas es su amor por el procónsul romano, con quien a pesar de su voto de castidad ha tenido dos hijos que mantiene ocultos en el bosque, al cuidado de la fiel Clotilde. Tras la orden de paz, Norma entona la conocida aria "Casta diva", y en la cabaletta ruega por el regreso de su amado Pollione ("Ah! bello a mi ritorna"). Cuando Norma sale de la escena entran Pollione y Adalgisa; ésta, pese a amar al romano, se siente culpable y está dispuesta a abandonarlo y consagrarse a su dios. Pollione insiste y le ofrece marchar los dos juntos a Roma. Tras debatirse, Adalgisa se decide a seguir su corazón. Mientras tanto, Norma comunica a Clotilde su dolor: Pollione ha sido reclamado al Tíber y ella teme que les abandone a ella y sus hijos. Adalgisa entra en escena y se confía a Norma: le confiesa que está enamorada, contra sus votos, de un hombre, y es correspondida por él. Norma se muestra condescendiente y comprensiva, pues conoce bien la situación en que se halla la muchacha, y no sospecha que el amado de Adalgisa es el propio Pollione. Libera a Adalgisa de sus votos y le desea la felicidad junto a su amado. Aparece entonces Pollione, y Adalgisa lo señala como su amor, encendiendo la furia de Norma. Postergada y abandonada, Norma está dispuesta incluso a dar muerte a sus hijos, aunque detendrá el cuchillo justo antes de asestarles un golpe mortal mientras ellos duermen. Su amor de madre es mayor que su despecho, y comprendiendo que será mejor para los nińos, los encomienda a Adalgisa para que ella y Pollione los críen en Roma. Adalgisa asegura a Norma que Pollione volverá a sus brazos, y en medio del dolor las dos mujeres se funden en un abrazo como amigas. De nuevo han de celebrarse los rituales, y el pueblo galo se prepara para levantarse contra el procónsul. Norma, mientras, confía en que Adalgisa persuada a Pollione de regresar con ella, pero Clotilde le anuncia que los ruegos de la joven han sido en vano, y Norma anuncia una terrible venganza. Golpeando el escudo sagrado, da la orden de marchar a la guerra. Oroveso le pide que indique cuál ha de ser la víctima propiciatoria que se sacrifique antes de la batalla. En ese momento, Clotilde anuncia que un romano ha sido descubierto en el claustro de las sacerdotisas. Traen preso a Pollione, y entregan a Norma un cuchillo para que dé muerte al profano. La vida de Pollione está en manos 
de Norma, y ella le pone como condición para salvarle que renuncie a Adalgisa, pero él se niega, y la sacerdotisa le dice que entonces le matará a él y hará que quemen a Adalgisa en la hoguera, acusándola de haber roto los votos. Pollione acepta su muerte pero implora piedad para Adalgisa. Norma ordena a su pueblo preparar una hoguera para una sacerdotisa perjura. Pero en el momento de desvelar la identidad, se acusa ella misma, y afronta su muerte. Este rasgo de valor y piedad conmueve a Pollione, que siente resucitar - demasiado tarde- su amor por Norma. Ambos se dirigen a la hoguera, no sin que antes Norma confiese a Oroveso la existencia de sus hijos, y ella y Polione le rueguen que tenga piedad de ellos, inocentes de las culpas de sus progenitores. La obra termina con la muerte de los amantes y el lamento de Oroveso.

El tercer nivel de operatividad lo ocupan Veleda y Sofonisba, que pueden ser incluidas en el linaje de Norma, a la que están unidas por evidentes coincidencias (mayores en el caso de Veleda, mucho más vagas en el de Sofonisba). Además, aunque hoy estas referencias nos parezcan remotas, y difícilmente vengan a nuestras mentes al escuchar y ver Norma, para los primeros espectadores de la ópera, Veleda era un referente actual, gracias a la exitosa novela de Chateaubriand, ya mencionada. En el caso de Sofonisba, existían varias versiones operísticas, aunque ya algo alejadas en el tiempo ${ }^{(27)}$. En cualquier caso, a nuestro juicio es evidente que su intensidad evocativa no es comparable a la de Medea ${ }^{(28)}$.

En el segundo nivel de operatividad se encontraría el personaje de Medea: no proporciona el argumento, pero actúa continuamente como reminiscencia de contraste, de modo que Norma alcanza su significado pleno cuando se reconoce en ella la relación (doble, afirmativa y negativa) con Medea. No estaría de más recordar que él mismo había escrito, en sus comienzos como libretista, una Medea para la música de Mayr, de modo que conocía bien el tema y con toda seguridad lo tuvo preserite para la creación de este nuevo libreto. Hemos tenido ocasión de comprobar que, mediado el siglo XIX, existía ya una cantidad considerable de óperas sobre la historia de Medea. De ellas, advierte David Kimbell, tres - la de Cavalli, la de Charpentier y la de Cherubini- eran obras maestras, cada una en su tiempo y lugar. La de Cherubini, en particular, habría sido un referente especialmente cercano, pues en las tres primeras décadas del siglo XIX se había convertido en una pieza básica del repertorio en los teatros de ópera italianos, en su versión traducida a

(27) Cabe destacar las de Tomasso Traetta y Gluck. Véase C. Clément, op. cit., 14.

(28) Acerca de la tradición de Veleda y su evocación en Norma, véase D. Kimbell, 1719. La relación con la figura de la cartaginesa Sofonisba es tratada por Clément, op. cit. 
esta lengua ${ }^{(29)}$. A esto habría que sumar las Medeas no operísticas: la literatura y la iconografía proveían de un corpus amplísimo, que crearía en el público una imagen poliédrica, tan imprecisa en la procedencia de cada detalle como inconfundible en su conjunto. Estamos hablando, por tanto, más que de una referencia literaria concreta, de la referencia a un arquetipo construido a partir de muchísimas versiones, que no se restringe a ninguna de ellas -aunque lógicamente las versiones operísticas, y la de Cherubini especialmente, serían las más inmediatas-, y que tampoco deja ninguna fuera, haciéndose así reconocible para todos los espectadores-auditores, sea cual sea la versión a través de la cual recuerden a Medea.

Brevemente, las similitudes entre Norma y Medea son las siguientes: 1) ambas están investidas de un poder sobrenatural (Norma es sacerdotisa de Irminsul y en escena la vemos invocando a la luna; Medea es una hechicera experta en venenos que rinde culto a Hécate, divinidad asociada a la luna, la magia y el mundo subterráneo; es, además, descendiente de ella); 2) tanto Norma como Medea son hijas del soberano de sus respectivos pueblos (Medea, de Eetes, rey de Cólquide; Norma, de Oroveso, jefe de la tribu gala - este parentesco de Norma con Oroveso no existía en el drama de Soumet, es una acertada innovación de Romani, que enfatiza así el lado humano, familiar, de la traición "de estado" cometida por Norma) - ; 3) ambas, Norma y Medea, se enamoran del enemigo extranjero y le salvan la vida gracias a sus poderes sobrenaturales, traicionando a su pueblo y a su padre por él; 4) las dos dan hijos al extranjero (dos, en ambos casos); 5) las dos son traicionadas por él, que prefiere los brazos de una mujer más joven; 6) tanto Medea como Norma tienen pensamientos de venganza: ambas piensan en causar la muerte a la nueva amada del hombre, y a sus hijos. Incluso, los argumentos que Norma esgrime a favor de esto último son los mismos en que se apoya Medea para llevar a cabo el infanticidio, y las dudas de ambas heroínas son muy similares, aunque se resuelven de diferente modo ${ }^{(30)}$.

Precisamente el que sean tantas y tan estrechas las similitudes, hace que las diferencias resalten más, y adquieran un significado particular. De

(29) Kimbell, op. cit., 17.

(30) Los versos en que Norma se debate entre las razones para dar muerte a los nin̄os y las razones para perdonarlos son los siguientes: "Teneri figli, / Essi, pur dianzi delizia mia, / essi nel cui sorriso / Il perdono del ciel mirar credei / Ed io li svenerò? / Di che son rei? / Di Pollione son figli: / Ecco il delitto. / Essi per me son morti! / Muoian per lui. / E non sia pena che la sua somigli. / Feriam Ah! No! Son miei figli!" (acto II, escena i); más adelante invoca piedad a Oroveso para los niños diciendo: "Deh! Non volerli vittime / del mio fatale errore! / Deh! Non trocar sul fiore / Quell'innocente età!" (acto IV, escena última). 
hecho, si exceptuamos la ambientación galo-romana del drama, los principales rasgos temáticos de Norma solo se comprenden plenamente si se atiende a cada uno de ellos como referencias (de afirmación y de negación) a Medea. Las diferencias pueden resumirse así:

1) Medea aparece siempre como una figura poderosa; emparentada con varias divinidades (entre las cuales destaca Hécate, diosa lunar), capaz de hacer obedecer a las fuerzas sobrenaturales gracias a su magia, que controla perfectamente. Los poderes de Norma, por el contrario, se reducen a una ingenua - aunque temporalmente efectiva - manipulación de los oráculos: su pueblo espera que ella anuncie que los dioses favorecen el ataque a los romanos, pero ella insiste en ordenar el mantenimiento de la paz, so pretexto de que los dioses así lo desean. La invocación a la luna de Norma, en la célebre aria "Casta Diva" no es la voz tonante de la hechicera poderosa que somete la naturaleza a su arbitrio, sino la de una mujer vulnerable que suplica la benevolencia y comprensión de la única divinidad en que ella parece verdaderamente creer. Por lo mismo, la ayuda que Norma presta a Pollione es mucho más modesta, en sus medios, que la que presta Medea a Jasón.

2) Los planes de venganza se gestan de modo muy distinto en cada una de las heroínas: aunque Medea actúa guiada por su arrebatada pasión que no conoce moderación ni temple, la decisión de matar a la nueva esposa de Jasón y a sus propios hijos tenidos con el héroe es absolutamente premeditada. Norma actúa de muy diferente modo: con respecto al motivo del infanticidio, en ningún momento la vemos planear en escena este crimen, como sí ocurre en el caso de la princesa de Cólquide. El tema se introduce repentinamente, cuando Norma aparece ante la cama donde sus hijos duermen, cuchillo en mano, dispuesta a darles muerte, alza su brazo armado... y justo antes de asestar el golpe mortal grita, despertando a los nińos, abrazándolos y besándolos como una buena madre.

3) Algunas importantes diferencias atañen a los protagonistas masculinos, Jasón y Pollione. Las que tienen que ver con su origen griego y romano, respectivamente, las veremos en el siguiente punto. No menos importante es señalar las distintas motivaciones que conducen a uno y otro al abandono de la amante y benefactora primera. En el caso de Jasón, desde la versión de Eurípides aparece caracterizado como un ambicioso cortesano (su faceta de valiente aventurero apenas es evocada) que cree que el alto destino del que es merecedor bien vale la utilización y posterior sacrificio de Medea (en la versión de Eurípides y las inspiradas por ella, nunca queda claro que llegase a amarla en algún momento, pero sí que supo 
aprovechar el amor de ella por él). Sus razones para contraer matrimonio con la princesa corintia no son mejores: en ningún momento dice amarla; sin embargo, es bien consciente de que ese matrimonio conviene a sus planes: se convertirá en rey gracias al matrimonio con una princesa griega (no de la bárbara Cólquide) y sus hijos (que también lo sean de Medea no importa demasiado) serán reyes también. Pollione, sin embargo, ha amado verdaderamente a Norma, $\mathrm{y}$ ahora está sinceramente enamorado de Adalgisa. No es un personaje grandioso, desde luego, y la ironía de Roger Alier al llamarle "coleccionista de sacerdotisas de Irminsul" (31) está perfectamente justificada, pero no es tampoco el seductor interesado de la tragedia clásica (recordemos que estos defectos habían sido muy subrayados por Thomas Corneille en su libreto para Charpentier). El peor defecto del Jasón euripideo todavía es el defecto de un héroe, pues la ambición que le lleva a manipular a las mujeres aún es una falla trágica, aunque sea la más baja de todas las posibles. El peor defecto de Pollione, sin embargo, es menos avieso, y precisamente por ello resulta mucho más trivial. Pero es que Norma es un melodrama del siglo XIX, y si Pollione carece de la (ya muy relativa) grandeza heroica de Jasón, es en la misma medida en que Norma (más aún el drama de Soumet que la ópera) carece de la profundidad trágica de Medea.

4) Especialmente interesante resulta el tratamiento del motivo de la extranjería. La condición de extranjera de Medea ya había sido destacada como posición de vulnerabilidad desde la tragedia de Eurípides, y muchas de las sucesivas revisiones del mito le concederán gran importancia. Veremos como en el siglo XX esta otredad se codifica incluso en términos de raza (en el teatro no musical, es especialmente memorable la Medea de Anouilh; en la ópera, Liebermann y Ursula Haas también han tratado este motivo). En la tradición, Medea ayuda a un extranjero (Jasón) en la tierra de ella, la Cólquide, pero desde el momento en que le sigue, pasa a ser una extranjera ella, en este caso en el mundo helénico: en la nave Argos, donde está rodeada de guerreros helenos, y más tarde en Corinto, donde sufre el abandono de Jasón (que prefiere el matrimonio con una princesa griega) y comete el infanticidio; tras su huida, continúa siendo extranjera en Atenas... y seguirá siéndolo hasta su regreso final — según algunas tradiciones - a la Cólquide. En Norma, sin embargo, el extranjero es el ro-

(31) R. Alier, Norma, 2002, 29. También Norma es para Alier un personaje de escasa nobleza: "(...) nadie repara en la dudosa catadura moral de Norma, una sacerdotisa sacrilega durante largo tiempo (...) que además ama al sojuzgador de su pueblo (...) manteniendo a su pueblo constantemente engañado con unas órdenes falsas del dios en el que, obviamente, cree muy poco." (Ibid). 
mano Pollione - aunque llegados a este punto deberíamos preguntarnos si los espectadores no veían a Pollione mucho más cercano a ellos, culturalmente, que el mundo exótico de Norma (que sería lo otro para Pollione y también para el público), aunque emocionalmente se pusieran del lado de la sacerdotisa celta. Pollione, sin embargo, no cambia a la bárbara Norma por una princesa del mundo romanizado (esto hubiese sido lo esperable, atendiendo al modelo del mito de Medea). Colonizador infatigable, elige a otra celta, Adalgisa. En el mito clásico extranjería y debilidad son circunstancias que van emparejadas (Jasón es extranjero y débil en Cólquide, y precisa la ayuda de Medea; Medea es extranjera y débil en Corinto, y es traicionada por Jasón). En Norma no ocurre exactamente así: Pollione es el extranjero, pero es fuerte y dominante, un conquistador por las armas y por el corazón, un ejemplo notable de colonizador racial, cultural y sexual, por expresarlo desde una perspectiva actual. El tema de la extranjería no solo se mantiene, sino que se acentúa, aunque cambia la formulación (el esquema Jasón-Creúsa / Medea ha pasado a ser Pollione / Norma-Adalgisa). Retomando la pregunta que hacíamos algunas líneas más arriba, insistiremos en la posibilidad de que, a pesar de que la atención y las simpatías del autor y de los espectadores se dirijan hacia Norma, ésta siga constituyendo lo exótico y ajeno, y Pollione, la "normalidad".

5) La solidaridad y ternura entre Norma y su rival Adalgisa es una diferencia fundamental con la historia de Medea. Norma se muestra comprensiva con la joven sacerdotisa enamorada, en la que se reconoce a sí misma al comienzo de sus amores con Pollione, $y$ a fin de que la joven no padezca como ella las penurias de un amor oculto, la libera de los votos. Más tarde, al saber que el amado de Adalgisa es Pollione, y que éste la corresponde, Norma se enfurece y está dispuesta a denunciar a Adalgisa (lo que supondrá su muerte) y a dar muerte a sus propios hijos. Pero cuando, por amor maternal, renuncia a matar a los niños, la sacerdotisa traicionada perdona también a su joven rival. Y no solo la perdona, sino que acepta el amor entre Adalgisa y Pollione, le desea la felicidad con él y le entrega a sus hijos para que ambos los cuiden en Roma. Incluso, aclara, "Non ti chiedo onori e fasci, / a' tuoi figli ei fian serbati. / Prego sol che i miei non lasci / Schiavi, abbietti, abbandonati". Es decir, que la actitud de Norma hacia sus hijos no solo se aparta de la de Medea, sino también de la del Jasón euripideo; éste, al justificar ante Medea su nuevo matrimonio, apela a los privilegios y honores que gozarán gracias a él sus dos hijos habidos con la princesa de la Cólquide. En nuestra opinión, este gesto supone el culmen de la renuncia de Norma y de su diferenciación de Medea, pues la sacerdotisa gala no solo se resigna a perder a su amante, sino que incluso confía a sus hijos a la mujer rival (lo que de algún modo supone traspasar- 
le a ella su realización como amante y como madre). Adalgisa, por su parte, responde generosamente, comprendiendo todo el dolor de la amante abandonada y comprometiéndose a que el romano vuelva a los brazos de Norma (aunque eso suponga renunciar ella misma al amor). La relación fraternal entre estas dos mujeres, enfrentadas por un mismo hombre que resulta muy inferior a ambas, es sin duda el sentimiento que con más profundidad aparece tratado en Norma. El correlato musical es claro: el de Pollione es uno de los papeles para tenor menos lucidos de la historia de la ópera, mientras que los dúos entre Norma y Adalgisa han sido cuidados con esmero por Bellini, y alcanzan una belleza ( $y$ una dificultad de ejecución) que justifica su popularidad.

6) La resolución final en relación con el infanticidio es la más llamativa de estas diferencias. Ya hemos mencionado que no existe en Norma la cuidadosa — si bien arrebatada - premeditación de Medea. La decisión final de Norma es la contraria, y no solo eso: Norma, además de no matar a sus hijos, logra salvar sus vidas. Primero, como ya hemos visto, los encomienda a Adalgisa, para que ésta los lleve a Roma cuando parta con Pollione, completando así su renuncia. Más adelante, cuando decide confesar su culpa ante la tribu y sacrificarse en la hoguera, teme que ellos sean también castigados, y suplica a su padre, Oroveso, que les permita vivir. Alega, en defensa de los nin̄os, que ellos son inocentes de los pecados de sus padres (exactamente el argumento inverso al utilizado por Medea). Norma traiciona a su religión y su pueblo por amor, y por el mismo motivo se inmola, pero es una madre. Por eso al final obtiene la dudosa recompensa de que Pollione se mate con ella al comprender la superioridad de una mujer capaz de una entrega total y descubrir demasiado tarde que era ella su verdadero amor. Más aún, Romani nos reserva la esperanza en un más allá que reúna a Pollione y Norma: "Là più santo / incomincia eterno amor!" En Norma, en fin, asistimos a la domesticación romántica de Medea. Algo que no extraña demasiado si consideramos el conservadurismo que impregna la mayor parte de las representaciones del hombre y la mujer en la ópera del XIX ${ }^{(32)}-\mathrm{y}$ en otros terrenos: no en vano este es el siglo en que se acuńa el ideal del ángel del hogar-.

En el siglo XX, la identificación entre Norma y Medea se hizo aún más estrecha por razones que rebasan lo artístico: la carismática y discutida

(32) Delgado, Arturo, "Personajes femeninos en la ópera: discriminación sexual, caracterización racial y misoginia”, en Marco, Aurora (ed.), Estudios sobre Mujer, Lengua y Literatuna. Universidad de las Palmas-Universidad de Santiago de Compostela, Santiago de Compostela, 1996, 53 y ss. 
Maria Callas interpretó ambos papeles en repetidas ocasiones (en el caso de la Medea de Cherubini, contribuyó con ello a rescatar para el repertorio una ópera que había caído en el olvido). Cuando su carrera como prima donna se encontraba en franco declive, Callas aceptó interpretar a la princesa de Cólquide en el cine, para la versión de Pasolini. En un plano extramusical y extraliterario - pero no menos real, y sí muy divulgadoesta especular relación entre Norma, Medea y Maria Callas se vio reforzada por la historia personal de los amores entre Callas y el magnate griego Aristóteles Onassis, atentamente seguida por la prensa rosa de la época (y presumiblemente por sus numerosos lectores). La imagen pública de Callas como abandonada bien pudo contar entre las razones que propiciaron la elección de la diva (sin experiencia cinematográfica) para protagonizar esta excelente película ${ }^{(33)}$.

Antes de finalizar el siglo XIX la ópera nos dejará todavía un buen número de Medeas. Giovanni Pacini (1796-1867) compone un melodrama trágico en tres actos titulado Medea, con libreto de Benedetto Castiglia. Esta ópera fue estrenada en el Real Teatro Carolino de Palermo, el 28 de noviembre de 1843, y re-estrenada, con modificaciones, dos años más tarde, en el Teatro Eretenio de Vicenza. Aunque su popularidad en Italia fue notable durante el siglo XIX, hoy la Medea de Pacini ha quedado fuera del repertorio [Oxford Guide, Poduska, Grove].

Ya mencionamos, anteriormente, la reutilización del libreto que Felice Romani había escrito para Mayr, en dos ocasiones: la versión con música de Prospero Selli se estrena en Roma, el 4 de febrero 1839; Salvatore Cammarano hace algunas modificaciones en el texto para la música de $\mathrm{Sa}$ verio Mercadante (1795-1870); esta versión, titulada Medea, se estrena el 1 de marzo de 1851, en San Carlo (Nápoles) [Oxford Guide; Grove, s.v. Mercadante, Saverio; Cammarano, Salvatore].

(33) Francisco Salvador Ventura, en su recomendable trabajo sobre esta nueva Medea, afirma que Pasolini fue bien consciente de las semejanzas personales que hacian de Callas la protagonista idónea para su película (aunque, sorprendentemente, los avatares sentimentales de la diva no se mencionan): "Durante la elaboración del guión de Medea afirma el propio Pasolini que siempre la tuvo [a Callas] in mente como su futura intérprete. Y ello no era en absoluto fruto de ningún componente caprichoso o circunstancial, sino de que en su propio perfil individual, en la trayectoria personal de la cantante, apreciaba el director italiano una cierta similitud con la vida de Medea en Corinto, ciudad en la que experimenta un cierto desarraigo en relación a su mundo primigenio. En efecto, la Callas procedía de un sustrato griego, un mundo arcaico y agrario a los ojos de Pasolini - bárbaro sería en el caso de Medea-; su formación se inscribió en los cánones establecidos por una educación burguesa; y vivía además lejos de su patria, en el extranjero, en concreto, en los Estados Unidos." ("La Medea de Pasolini [1969]. Una estética contracultural de lo mítico", en López, Aurora y Andrés Pociña (eds.), op. cit., vol. II, 1011). 
El 25 de diciembre de 1874, en Gotha, se estrena la Medea de Otto Bach (1813-1893) [Oxford Guide].

Asimismo cabe mencionar a Zdenĕk Fibich (1850-1900), compositor checo que al parecer habría comenzado a componer, durante su adolescencia, una Medea. El libreto era también obra suya, pero la ópera quedó inconclusa y hoy está perdida [Oxford Guide; Grove, s.v. Fibich, Zdeněk].

A lo largo del siglo XX, Medea ha continuado viva en la ópera, en dos sentidos. Primeramente, a través de la presencia en el panorama operístico (en representaciones y grabaciones) de las composiciones hasta aquí vistas. Se ha recuperado para el repertorio la ópera de Cherubini; también, aunque en menor medida, han sido objeto de atención la Medea de Charpentier, el Giasone de Cavalli y la Medea in Corinto de Mayr. En segundo lugar, porque nuevas Medeas se han sumado a esta tradición - algunas de ellas, como veremos, con un claro espíritu subversivo.

Entre 1902 y 1904, Vincenzo Tommasini (1878-1950) compone la música y escribe el libreto de una Medea en tres actos, estrenada el 8 de abril de 1906, en el Teatro Verdi de Trieste [Oxford Guide; Grove Dictionary, s.v. Tommasini].

El compositor esloveno Slavko Osterc (1895-1941) compone en 1930 una Medea en un acto, con libreto del propio Osterc a partir de la ópera de Eurípides, que se estrenó en Liubliana, el 27 de febrero de 1932 [Oxford Guide; Grove, s.v. Osterc].

Otra Medea operística sería la debida a Lehman Engel (1910-1982) [Oxford Guide; Grove en la entrada correspondiente a Lehman, no incluye ninguna referencia a una $M e d e a]$.

Darius Milhaud (1892-1974) compuso una Médée en un acto, con libreto de Madeleine Milhaud, que se estrenó el 7 de octubre de 1939, en Antwerp (Opéra Flamand) [Oxford Guide; Grove, s.v. Milhaud, Darius].

Pietro Canonica (1869-1959) escribe una Medea estrenada el 12 de mayo de 1953 en el Teatro dell'Opera en Roma [Oxford Guide].

Edward Staempfli es autor de una Medea en tres actos, con libreto del propio Staempfli, a partir del drama de F. Grillparzer Medea (1820); esta ópera habría sido concluida en 1954 , pero no ha sido representada [Oxford Guide; Grove, s.v. Staempfli, Edward].

Andor Kovách (1915) compone en 1960, Médée; él mismo es el autor del libreto, a partir del drama de Anouilh (1946) [Oxford Guide].

Bernd Alois Zimmermann (1918-1970) trabajó durante años en una ópera a partir del drama Médée, de Hans-Henny Jahnn (1926 primera ver- 
sión, 1959 segunda versión) ${ }^{(34)}$, pero nunca llegó a dar forma definitiva a esta labor [Oxford Guide, Grove, s.v. Zimmermann, Bernd Alois].

The Oxford Guide... da noticia del estreno en Salónica, el 16 de agosto de 1976, de una Medea de Theodore Antoniou (1935). Según The Oxford Guide..., Antoniou sería autor de la música y el libreto, a partir de la tragedia de Eurípides. The New Grove Dictionary, en la entrada correspondiente a Antoniou, no da noticia de esta obra. No nos parece que deba incluirse esta referencia entre las Medeas re-creadas para la ópera: en la página web del compositor griego puede consultarse una lista completa de todas sus obras (entre las que se cuentan varias óperas, composiciones para orquesta, para música de cámara, para coros, etc.). En esta lista aparecen consignadas no una, sino dos Medeas: la primera representada, efectivamente, en Salónica, aunque la fecha de estreno que se facilita es el 8 de febrero de 1976; la segunda, estrenada en Atenas, en 1985 (no se precisa más). En ambos casos se trataría de versiones de la tragedia de Eurípides, y no de óperas [http://www.mmb.org.gr/eem_en/composers/ Antoniou_Theodore/Antoniou_Works.htm].

El 3 de mayo de 1979, en el New England Conservatory, de Boston, se estrena Medea, ópera de Ray Luke (1926) con libreto de Carveth Osterhaus a partir de Eurípides [Oxford Guide].

Gavin Bryars (1943) es autor de una Medea, creada en colaboración con el dramaturgo y director de escena Robert Wilson. Esta ópera se estrenó en Lyons, el 23 de octubre de $1984^{(35)}$.

Sobre el texto de la obra Medeamaterial de Heiner Mulher, Pascal Dusapin (1955) compone en 1990 una ópera homónima, estrenada el 13 de marzo de 1992, en el Théâtre de la Monnaie (Bruselas) [Poduska; http:// mac-texier.ircam.fr/].

(34) Maria Manuela Gouveia Delille, "O mito de Medeia em Dois Dramas Alemáes do Século XX", en AA.VV., Medeia no Drama Antigo e Moderno, Centro de Estudos Clássicos Humanísticos da Faculdade de Letras da Universidade de Coimbra, Coimbra, 1991, 219. Gouveia Delille facilita también la referencia de una edición moderna de la segunda versión de la obra de Jahnn (Medea, Reclam, Stuttgart, 1985; véase Delille, op. cit., 219, n. 2). La profesora Gouveia Delille ha subrayado en este trabajo la importancia de la Medea de Hans Henny Jahnn, haciendo hincapié sobre lo que esta obra tiene de recuperación del espíritu helénico $y$ aun pre-helénico del mito, $y$ sobre la carga erótica y racial - la Medea de Jahnn es una princesa negra- que deposita en él.

(35) The Grove Dictionary of Opera, en la entrada correspondiente a Robert Wilson no menciona esta colaboración, y el único trabajo que atribuye a Wilson relacionado con el tema de Medea es la dirección de una Médée de Charpentier, en Lyons, en 1984. Creemos, no obstante, que la obra representada no fue otra que la creada por Gavin Bryars y el propio Wilson [http://www.gavinbryars.com/Pages/medea_first_note.html]. 
En la década de los 90, Hans-Jürgen von Bose (1953) trabajó en una ópera a partir de la historia de Medea, pero no llegó a concluirla [Grove s.v. Bose, Hans-Jürgen von].

Mikis Theodorakis (1925) es autor de la música y el libreto de una Medea, ópera en dos actos, estrenada en el 1 de octubre de 1991, en el Teatro Arriaga, de Bilbao [http://www.mikis-theodorakis.net/].

Desde un punto de vista argumental, muchas de estas óperas contemporáneas se caracterizan por una actitud revisionista y actualizadora del mito, actitud que en otros géneros, y particularmente en el teatro no musical, ya había dado sus frutos (piénsese por ejemplo en la Medea de Anouilh). A este respecto, es paradigmático el caso de las obras nacidas de la colaboración entre Rolf Liebermann y Ursula Haas. Esta escritora alemana es autora de una novela titulada Freispruch für Medea $(1987)^{(36)}$, y de varios textos sobre la princesa parricida para partituras de Rolf Liebermann. La primera de las colaboraciones entre Liebermann y Haas dio como fruto no una ópera, sino una cantata, Medea Monolog (aunque éste es el título con que aparece la composición en la grabación comercializada, en el cuadernillo que acompaña al compact-disc el texto de Haas aparece precedido del mismo título de su novela, Freispruch für Medea). Fue estrenada en el Musikhalle, de Hamburgo, el 26 de agosto de 1990 [Podus$\mathrm{ka}^{(37)}$. Se trata de un monólogo dramático para soprano, pero anuncia ya el carácter revisionista y subversivo de la ópera Freispruch für Medea. En el monólogo se insiste sobre la condición de forastera de Medea; más aún, la propia princesa subraya su otredad racial ${ }^{(38)}$ : "Schwärzer wehen meine Locken, dunkler wird meine Haut" ("Más negros ondean mis rizos, más oscura se vuelve mi piel'); "(...) Die fremde Wilde ganz in deiner Hand" ('La salvaje extraña enteramente en tus manos'); "Höre den Schrei deiner Negerin, Held von meinen Gnaden! / Ich hasse eure weiße Haut! (...) ('Escucha el grito de tu negra, / héroe de mis clemencias. / ¡Odio vuestra

(36) Maria Manuela Gouveia Delille, en el trabajo ya citado, menciona a varias escritoras alemanas que en el siglo XX han reinterpretado desde una perspectiva feminista el mito de la princesa de la Cólquide, y se detiene especialmente en la novela de Haas, mencionando también el texto para la cantata de Liebermann (op. cit., 225).

(37) Donald Poduska recoge esta colaboración de Liebermann y Haas, aunque da como título Medea-Material, que es en realidad, como hemos visto, una obra de Dusapin (ésta, por otro lado, también aparece en la lista de Poduska, como Medeamaterial).

(38) Como ya hemos dicho, éste de la otredad racial es uno de los aspectos que más interés han despertado en las versiones del mito de Medea realizadas a partir de finales del siglo XIX, y la ópera no escapa a dicha tendencia: "El tema en cuestión [se refiere a la representación de la mujer en la ópera] va estrechamente relacionado con otros, como al discriminación racial o las diferencias sociales." (A. Delgado, op. cit., 63). 
piel blanca!') ${ }^{(39)}$. También aparece subrayada la oposición entre el mundo viril, dominante, de Jasón, y la subordinación humillante de las mujeres, en cuyo nombre habla Medea. Una interesante innovación respecto a la tradición euripideana -innovación que se encontraba ya en la novela de Haas y se mantendrá en la ópera - es la transformación del motivo del infanticidio: ahora Medea aparece encinta, y reniega del hijo de Jasón que lleva en sus entrańas: "Jason, Vater unseres ungeborenen Kindes! / Leg'die Hand auf meinen Leib! Es lebt der Bastard in meinem Schoß, / der Mischling aus Ost und West. (...) Jason. Ich will kein Kind von Dir! / Kein Kind den Mächtigen der Welt! / Wer lieben kann, der kann auch töten!" (¿Jasón, no quiero ningún hijo tuyo! / JJamás un hijo para los poderosos del mundo! / ¡Quien sabe amar también sabe matar!') ${ }^{(40)}$. Sin embargo, no se encuentra aún el componente de subversión queer de la ópera (donde Jasón abandona a Medea no por una princesa, sino por un joven sacerdote de Apolo, hijo de Creonte, llamado también Creonte).

El libreto, del que hay dos versiones, lleva el mismo título de la novela de Haas, Freispruch für Medea (incluido también, como veíamos, al frente del texto de la cantata Medea Monolog). En la primera versión, se trataba de una ópera en dos actos. El estreno tuvo lugar en 1995, en la Staatsoper, de Hamburgo [Poduska]. Aunque Liebermann moría en 1999, una nueva versión ampliada de dos a tres actos se representó en 2001, en el Stadttheater, de Berna, con el título de $M e d e a$, bajo la dirección escénica de Philippe Godefroid y Françoise Terrone, y en el año 2002, en el Teatro de la Opera de la Bastilla, bajo la dirección escénica de Jorge Lavelli.

La vuelta de tuerca sobre el motivo de la infidelidad de Jasón, al presentarlo enamorado de un joven, ha llevado a algunos críticos, como Dominique Fernandez, a afirmar que esta Medea es la primera ópera abiertamente gay ${ }^{(41)}$. Otros críticos han matizado esta opinión, que con-

(39) Agradecemos a Vincent Gatzsch (Universidad de Potsdam) su amabilidad al traducir al español, para este trabajo, los versos de Ursula Haas, de los cuales no se ha editado ninguna traducción en español.

(40) Esta idea se encontraba ya en la tragedia de Séneca, donde Medea, ante el horror de Jasón por la muerte de los niños, añade: "in matre si quod pignus etiamnunc latet, / scrutabor ense viscera et ferro extraham." (vv. 1012-1013). En su edición crítica, Leo elimina estos versos del texto senequiano (F. Leo, edición y aparato crítico de L. Annaei Senecae Tragoediae, vol. II, Weidmannsche, Berlín, 1963, 131). Auténticos o espúreos, lo que aquí nos interesa es que la tradición los integró en el texto de la tragedia, y así se ha leído ésta durante siglos, por lo que dichos versos han podido actuar como antecedente de la idea del aborto expresada por Haas.

(41) Anteriormente, el propio Dominique Fernandez habia dedicado un capítulo de su libro El rapto de Ganimedes a esta cuestión. El capítulo, significativamente titulado "De 
sideran sesgada por centrarse exclusivamente en un elemento de la obra (y no más importante que otros, como el conflicto racial), o incluso han negado el valor liberador o regenerador de esta relectura del mito que no deja bien parada a ninguna de las dos partes. El propio Liebermann declaró que su propósito había sido escribir una "ópera anti-macho" (lo que supone un claro matiz respecto de la etiqueta "ópera gay").

Todavía en octubre de 2002 se ha estrenado en la Fenice de Venecia una nueva versión de la historia de Medea, libremente basada en la tragedia de Eurípides: la "ópera-vídeo" Medea, de Adriano Guarnieri.

La eficacia de los encantos de Medea está demostrada por la atención que le han dedicado otras formas dramáticas y, en general, literarias, así como las artes plásticas. Esta popularidad, ya lo hemos visto, explica en parte la recurrencia del tema en la ópera como efecto de un impulso recibido desde los otros campos (el teatro, siempre; la novela, el cine incluso). Pero Medea añade a los que le son habituales un encanto más, cuando de ópera se trata, pues establece, con respecto al modelo habitual de tratamiento de la mujer en los libretos, una relación de afirmación y negación. Afirma Arturo Delgado que la exaltación de las voces femeninas y de la figura de la prima donna por encima de sus compañeros masculinos tiene como contrapartida el tratamiento que reciben, en los argumentos, los personajes femeninos: “(...) son los más castigados por la trama argumental: son abandonadas, despreciadas y condenadas a morir aunque al mismo tiempo sean admiradas, deseadas o adoradas (...) Suelen ser, aun en la ópera moderna, el elemento cargado de culpas más graves" (42). Además, Delgado señala que las protagonistas femeninas de la ópera, aunque desencadenantes de la acción, suelen tener en ella un papel pasivo, y que, en los casos en que, al final, en lugar de castigadas son recompensadas (la minoría), esta recompensa se efectúa a costa de otra mujer ${ }^{(43)}$. Las muchas y diversas Medeas que aquí hemos mencionado se ajustan solo en parte a este tratamiento general que el género operístico ha dispensado a los personajes femeninos, y en parte se oponen a él. Transgresora siempre, Medea es tan ubicua precisamente porque participa del esquema general sin limitarse a reproducirlo mecánicamente, resquebrajándolo en algún punto. En el

Mozart a Britten, o sobre la dificultad de llevar a la escena a héroes operísticos homosexuales", analiza la expresión de la homosexualidad en la ópera, desde aquellas obras en que ésta aparece más crípticamente cifrada, como Eugenio Onikguin, hasta ejemplos que han planteado el tema de manera más explícita, como las obras de Benjamin Britten, y especialmente Billy Budd y Peter Grimes. Véase D. Fernandez, El napto de Ganimedes, Tecnos, Madrid, 1992, 171-188.

(42) A. Delgado, op. cit., 41.

(43) Ibid., 44. 
esquema más habitual en los libretos, la mujer aparece pasiva y relegada al ámbito doméstico y privado ${ }^{(44)}$; Medea, desde el interior de ese espacio, rompe la barrera y extiende hacia el exterior las consecuencias de los actos que realiza en él: su actividad mágica (desplegada en privado, pero de consecuencias públicas), el regalo de la túnica (prenda femenina que ella utiliza para infligir la muerte) y, sobre todo (por representar la máxima infracción contra el hogar) la muerte de los hijos. Además, la antigüedad y complejidad del mito hacía ya tiempo que lo había convertido en una constelación de motivos, y la elección de uno u otro permitía seguir presentando un tema conocido y prestigioso de acuerdo con los gustos de cada época. El mismo mito que servía a Cavalli y Cicognini para poner en escena los amores contrariados de Hipsípila, Jasón y Medea, ofrecía atractivos a la tragèdie en musique francesa del siglo XVIII por su espectacularidad escénica (que permitía dar a la obra la forma muy apreciada de pièce à machines) $\mathrm{y}$ ha seducido a la posmodernidad por las posibilidades de reflexión en torno a la otredad racial y sexual de su argumento.

Repudiada, condenada, perseguida, maldita, Medea ha sabido esperar, hacer creer a sus enemigos que era débil o que, simplemente, había decidido huir y ocultarse para siempre. Pero no fue así: Medea nunca se marchó del todo, y su magia sigue siendo poderosa. Los ejemplos propuestos a lo largo de las páginas de este trabajo, aunque muy someramente expuestos por razones de espacio, son fiel testimonio de un poder de seducción que se ha mantenido intacto a través de los siglos y de los hombres. Muchas han sido sus víctimas hasta ahora, pero también muchos los que habrán de caer aún rendidos a él. El hechizo de Medea no se ha roto.

\section{BIBLIOGRAFIA}

AA.VV., Medeia no Drama Antigo e Moderno, Centro de Estudos Clássicos Humanísticos da Faculdade de Letras da Universidade de Coimbra, Coimbra, 1991.

- Norma. Lavant Scene Opéra, 29, 1980.

ALER, Roger, Traducción, estudio y comentarios. Norma de Vicenzo Bellini. Libreto original italiano de Felice Romani, inspirado en la tragedia Linfanticide, de Alexandre Soumet. Robinbook, Barcelona, 2002. Comentarios muy valiosos, edición muy cuidada del libreto con anotaciones de gran utilidad para la audición de la ópera.

- Historia de la ópera, Ma non troppo, Barcelona, 2002.

(44) Ibid, 45-46. 
Andioc, R. y Miraille C., Cartelera teatral madrileña del siglo XVIII (17081808), 2 vols., Praises Universitaires, Mirail, Toulouse, 1996.

Apolonio DE Rodas, Las Argonáuticas, Cátedra, Madrid, 1986. Edición y traducción de Máximo Brioso.

BÉGaud, J., "L'oeuvre à l'affiche", L'Avant Scene Opera, 68, 1993, 123-124.

Brrto, Manuel Carlos de, Opera in Portugal in the Eighteenth Century, Cambridge University Press, Cambridge, 1989.

Brunel, Pierre (dir.), Dictionnáire des Mythes Féminins, Éditions du Rocher, Paris, 2002.

CessaC, C., "Eléments pour une biographie", Lavant Scene Opéra, 68, 1993, 422.

Christie, W., "Laventure de la re-création", Médée. L'Avant Scene Opéra, 68, 1993, 118-122.

Clément, C., "Norma, Médée, Sophonisbe: de la séduction à la résistance", L'Avant Scéne Opéra, 29, 1980, 12-15.

CoRneIlue, Pierre, Oeuvres complètes, tt. I-III, Gallimard, Paris, 1980-1987.

DancourT, Michèle, "Médée dans la culture européenne du XX" siècle", en Brunel, Pierre (dir.), Dictionnaire des Mythes Féminins, Éditions du Rocher, Paris, 2002, sub voce Médée, 1288-1292.

Davidson ReID, J., The Oxford Guide to Classical mythology in the Arts, vol. II, Oxford University Press, Oxford, 1993.

Delgado, Arturo, "Personajes femeninos en la ópera: discriminación sexual, caracterización racial y misoginia", en Marco, Aurora (ed.), Estudios sobre mujer, lengua y literatura, Universidad de Las Palmas-Universidad de Santiago, Santiago de Compostela, 1996, 37-63.

Fernandez, Dominique, El rapto de Ganimedes, Tecnos, Madrid, 1992. Traducción de Beatriz Ibarra Elorriaga.

Gouveia Delmle, Maria Manuela, "O Mito de Medeia em Dois Dramas Alemães do Século XX", en AA.VV., Medeia no drama antigo e moderno, Centro de Estudos Clássicos Humanísticos da Faculdade de Letras da Universidade de Coimbra, Coimbra, 1991, 219-225.

GuarNierI, Adriano, Medea, Fondazione Teatro La Fenice de Venezia, Venecia, 2002.

KimBelL, D., Vincenzo Bellini: Norma, University Press, Cambridge, 1998.

LEO, F., edición y aparato crítico de L. Annaei Senecae, Tragoediae, vol. II, Weidmannsche, Berlín.

Moormann, Eric M. y UitTerhoeve, W., De Acteón a Zeus. Temas sobre la mitologia clásica en la literatura, la música, las artes plásticas y el teatro, edición española de Jesús Martínez Sánchez, Akal, Madrid, 1997. 
Moreau, Alain, "Médée Antique", en Brunel, Pierre (dir.), Dictionnaire des Mythes Féminins, Éditions du Rocher, Paris, 2002, sub voce Médée, 1280-1283.

Oliveira Barata, J., "Utopia e Realidade: os encantos de Medeia e o anel de Sacatrapo", en AA.VV., Medeia no drama antigo e moderno, Centro de Estudos Clássicos Humanísticos da Faculdade de Letras da Universidade de Coimbra, Coimbra, 1991, 101-134.

PinTIAuX, Benjamin., " La tragédie amoureuse dans la tragédie en musique: l'exemple de Médée et Jason de Pellegrin et Salomon (1713)", en http:/ www.brown.edu/Research/Equinoxes/journal/issue2/eqx2_pintiaux.html.

Consulta realizada con fecha 19 de abril de 2004 .

Poduska, Donald M., "Classical Myth in Music", Classical World, 92.3, 1999, 195-276. También en http:/www.jcu.edu/myth\&music, con información más actualizada.

RuJCK, Camille de, "La Medea de Liebermann dans la presse", en http://forumopera.com/actu/medea.htm. Consulta realizada con fecha 5 de mayo de 2004.

Roccatagliati, Alessandro, Felice Romani librettista, Libreria Musical Italiana, Lucca (Italia), 1996.

Rocha Pereira, M.H., "O Mito de Medeia na Poesia Portuguesa", en López, Aurora y Andrés Pocina (eds.), Medeas. Versiones de un mito desde Grecia hasta hoy, Universidad de Granada, Granada, 2002, vol. I, 70-85.

Russo, Paolo, "Medea in Corinto" di Felice Romani, Storia, fonti e tradizioni, Olschki, Firenze, 2004.

SADIE, Stanley (ed.), The New Grove Dictionary of Opera. IV vols. MacMillan Press Limited, London-New York, 1992.

Salvador Ventura, F., "La Medea de Pasolini (1969). Una estética contracultural de lo mítico", en Aurora López y Andrés Pociña (eds.), Medeas. Versiones de un mito desde Grecia hasta hoy, vol. II, 1009-1032.

SiLva, M." de F., "Tragédia feita comédia. Os Encantos de Medeia do Judeu", en López, Aurora y Andrés Pociña (eds.), Medeas. Versiones de un mito desde Grecia hasta hoy, vol. II, 819-846.

STERnfeld, F.N., The birth of Opera, Clarendon Press, Oxford, 1995.

Werly, Patrick, "Médée du XVI" au XVIII" siècle", en Brunel, Pierre (dir.), Dictionnaire des Mythes Féminins, Éditions du Rocher, Paris, 2002, sub voce Medee, 1283-1288.

ZOPELL., L., L'opera come racconto. Modi narrativi nel teatro musicale dell'Ottocento, Marsilio, Venezia, 1994. 


\section{DISCOGRAFIA}

Esta discografía no es, en modo alguno, completa. Para varios de los títulos disponemos de una única grabación, pero en varios casos son muy numerosas las versiones disponibles, por lo que hemos optado por alguna de las más célebres o asequibles. No hemos incluido las selecciones de fragmentos. El artículo de Donald Poduska "Myth in music", citado en la bibliografia, proporciona la referencia de todas las grabaciones de aquellas óperas incluidas en él. En la edición del libreto de Norma preparada por Roger Alier, citada en la bibliografia, se incluye una completa discografía comentada.

BENDA, Jiří Antonín (Georg), Medea. ACCORD 202622, NAXOS 8.553346.

CAVAL, Francesco, Giasone. HARMONIA MUNDI FRANCE 901282/4.

CHARPENTIER, Marc-Antoine, Médée. ERATO 96558, HARMONIA MUNDI FRANCE 901139/4, 901316/8.

CHERUBinl, Medea. ANGEL 63625, ARKADIA 428, 464, 516, CLAQUE 2005/6, DENON 7336/7, EMI 63625, 67909, FONIT-CETRA 3002, FORTISSIMO 3002, GALA 100.555, HUNGAROTON 11904/5, HUNT 516, 34028, MELODRAM 26005, 26016, 26022, 27087, MYTO 91136, NEWPORT 85622, NUOVA ERA 7253/4, VERONA 27088.

MAYR, Giovanni Simone, Medea in Corinto. MYTO 993.211, OPERA RARA 11 ,

PACINI, Giovanni, Medea ARKADIA AKADEMIA 146.

DUSAPIN, Pascal, Medeamaterial. Harmonia mundi HCM 9052151993.

LIEBERMANN, Rolf, Medea-Monolog NAXOS 8.555.884.

- Freispruch für Medea (primera versión) Musiques Suisses 6126.

THEOdORAKIS, Mikis, Medea Intuition INT 33202.

\section{PÁGINAS WEB CONSULTADAS}

- http://www.cesar.org.uk/cesar2/books/parfaict_1767/index.php Consulta realizada el 21 de abril de 2004.

- http://www.mmb.org.gr/eem_en/composers/Antoniou_Theodore/Antoniou_Works.htm

- http://mac-texier.ircam.fr/

- http://www.cesar.org.uk/cesar2/

- http://www.mikis-theodorakis.net/

- http://www.gavinbryars.com 